\title{
استخدام قانون بنفورد في كشف إدارة الإرباح ـ بالتطبيق على عينة هن الشركات المدرجة في سوق العراق للاوراق المالية
}

\author{
أ. م. د. عباس حميد يحيى التميمي الباحث/ حكيم حمود فليح الساعدي \\ كلية الادارة والاقتصاد- جامعة بغدادـ قسم المحاسبة
}

يعد صافي الإرباح المنثورة في الكثوفات المالية السنوية المعلنة للثركات المدرجة في الأسواق

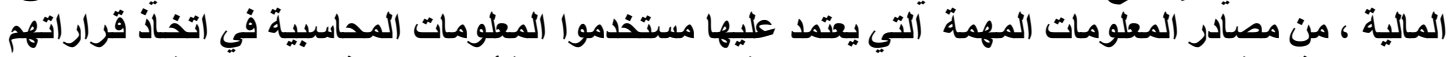

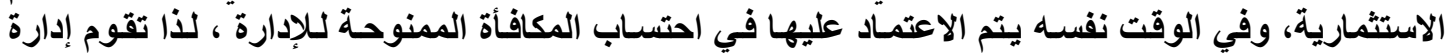

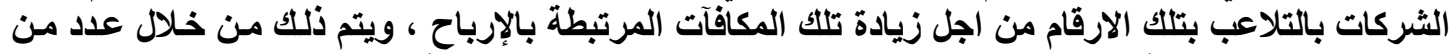

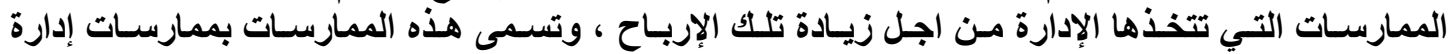

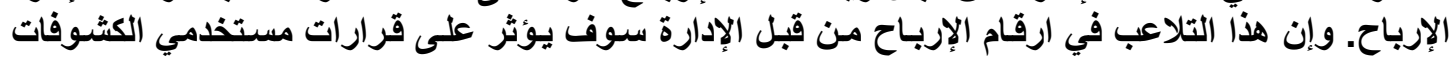

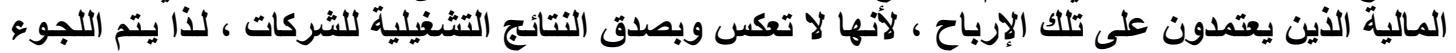

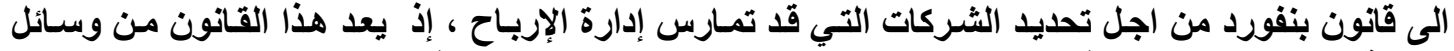

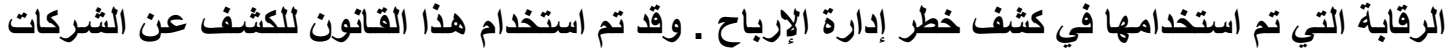

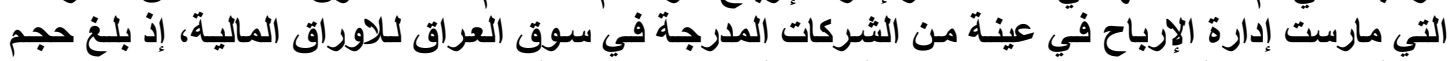

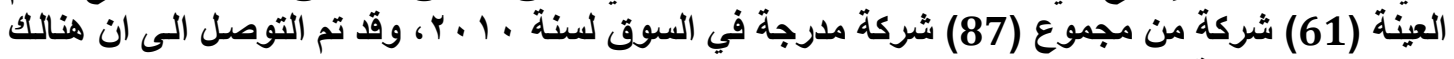

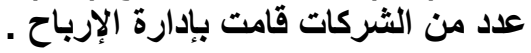

المصطحات الرئيسية للبحث: إدارة الإرباح- قانون بنفورد- التحليل الرقمي.

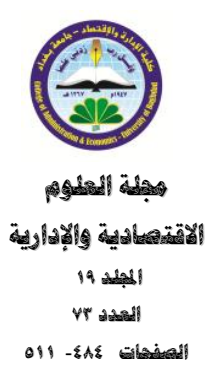

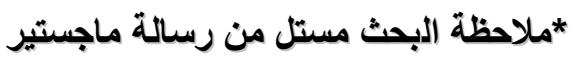




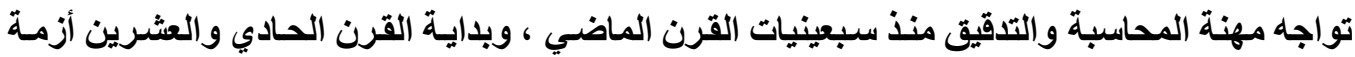

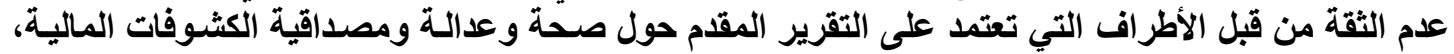

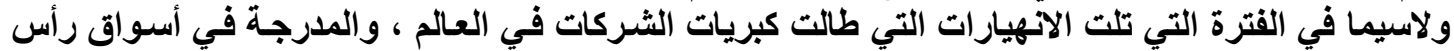

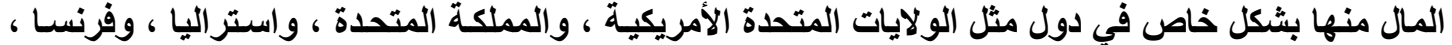

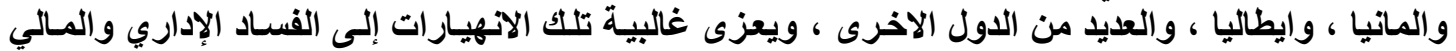

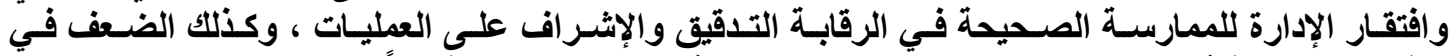

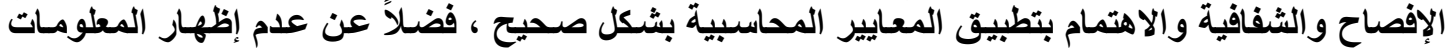

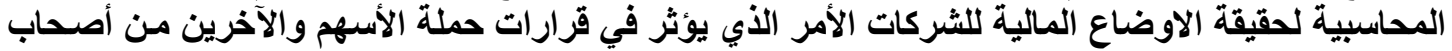

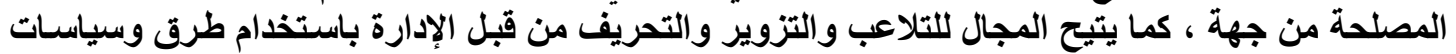

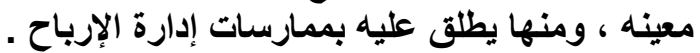

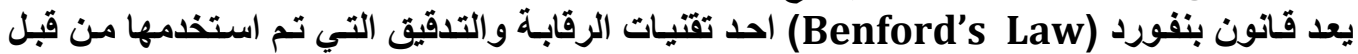

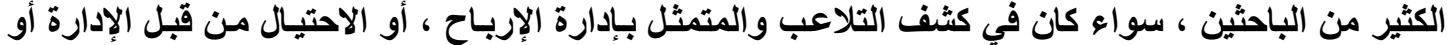

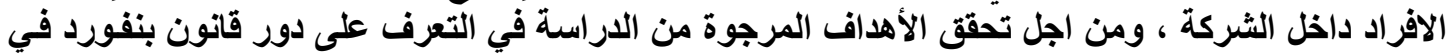

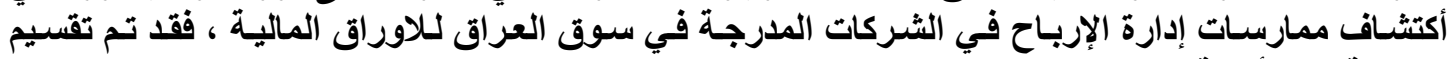

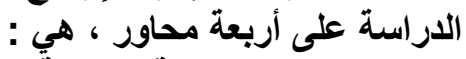

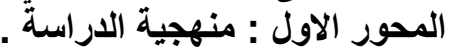

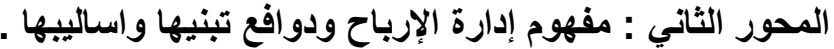

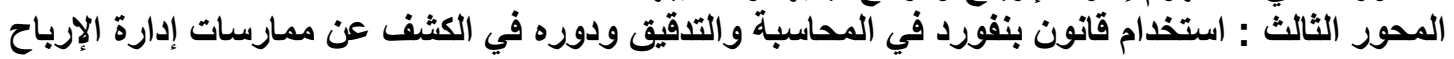
المحور الاخير : الاستنتاجات والتوصيات 


\section{المهور الاول/ هنهمية الدراسة}

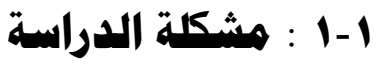

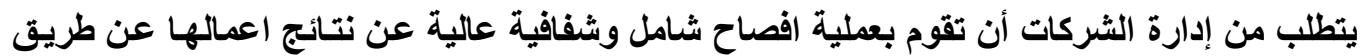

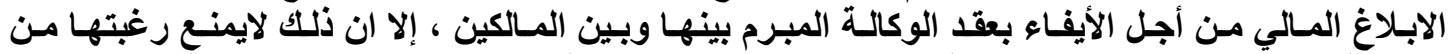

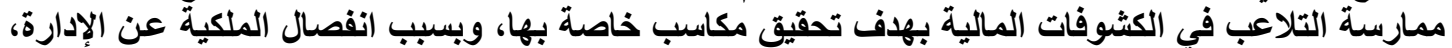

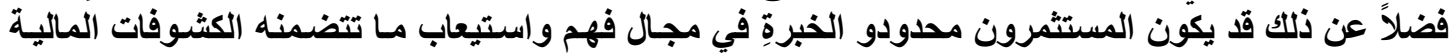

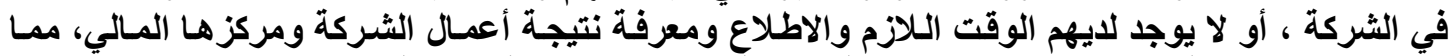

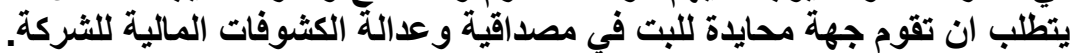

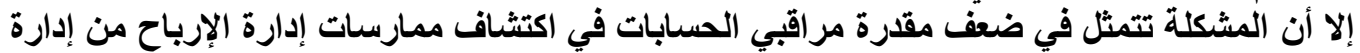

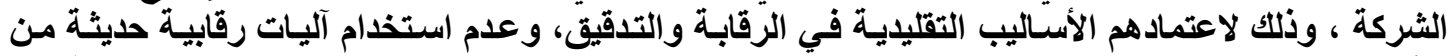

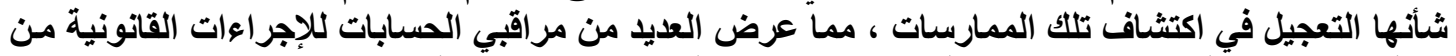

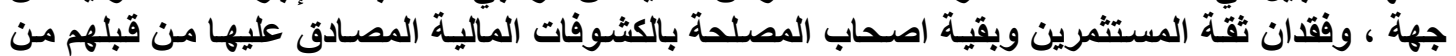
جهة اخرى .

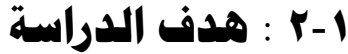

\section{تهوف الاراسة إلى تحقيق ما يأتي :}

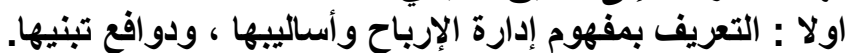

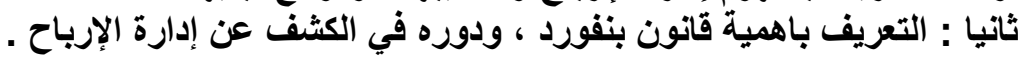

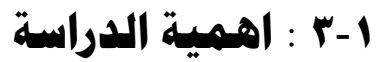

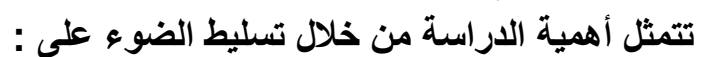

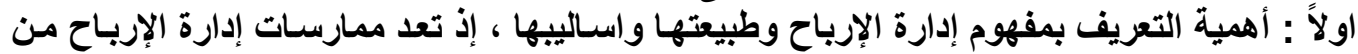

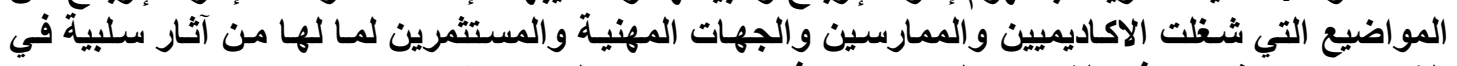

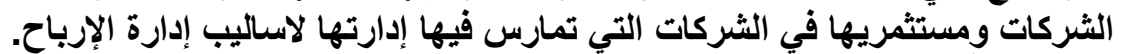

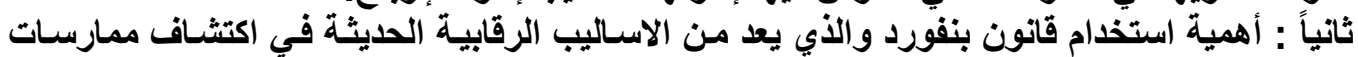
إدارة الإرباح في الاسواق المالية .

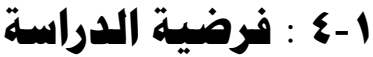

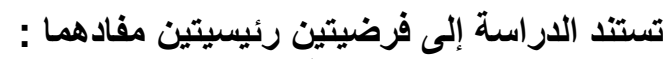

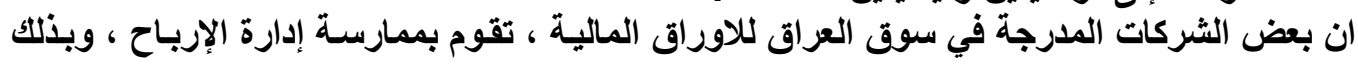

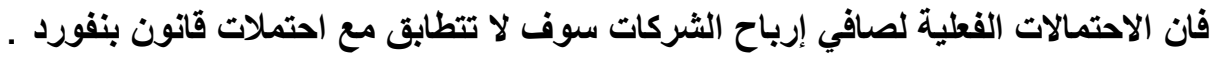

\section{ا -0 : هجتمع الدراسة وعينتها}

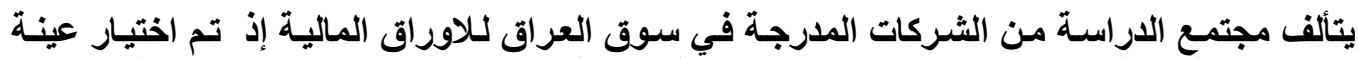

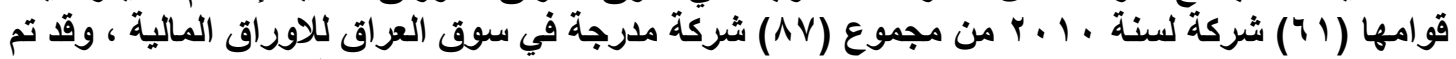

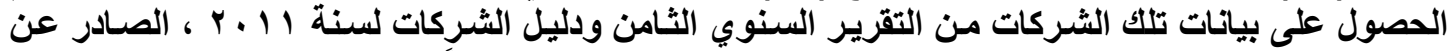

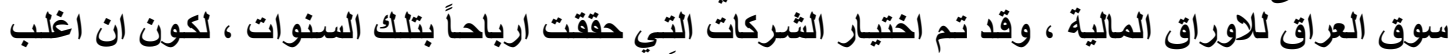

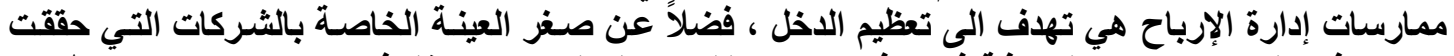

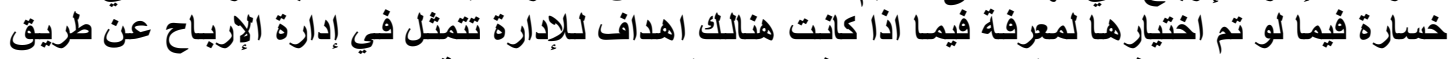

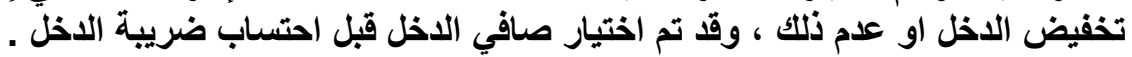




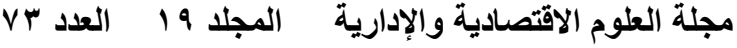

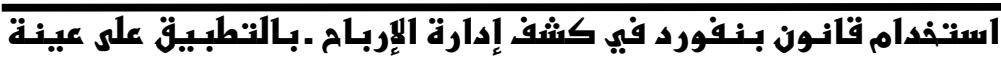

من الشركات المدرجة في سور العراق للاوراؤ المالية

الجدول رقم (1) القطاعات الاقتصادية عينة البحث

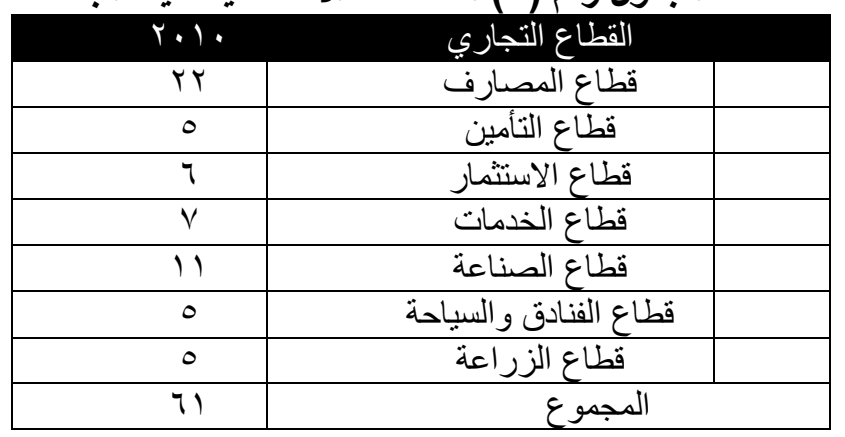

\section{المهور الثاني/ هفهوم إدارة الإرباح ودوافع تبنيدها واساليبهها}

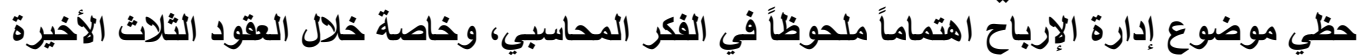

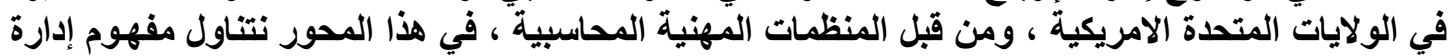

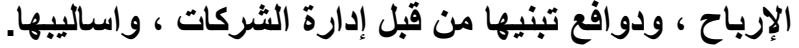

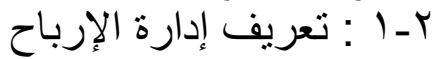

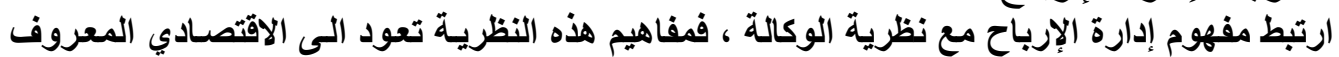

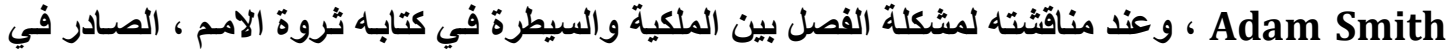

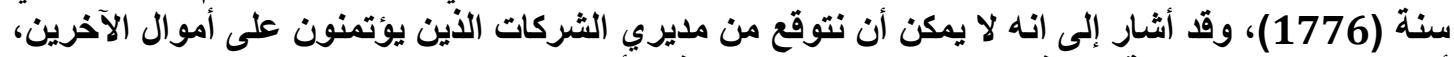

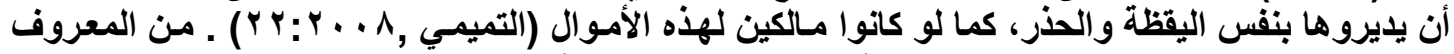

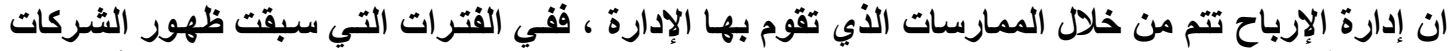

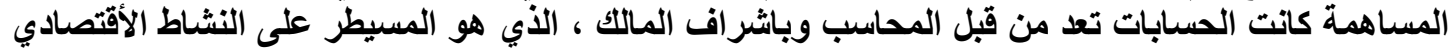

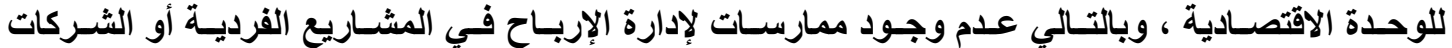

التضامنية.

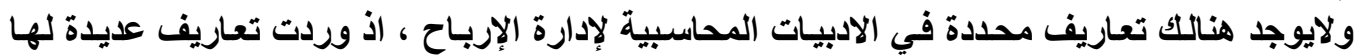

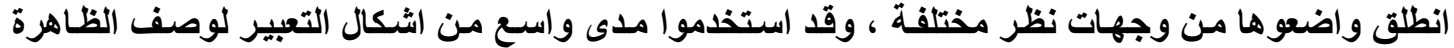

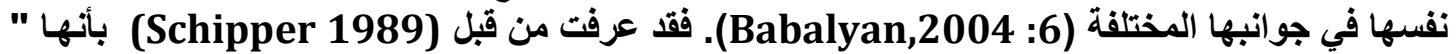

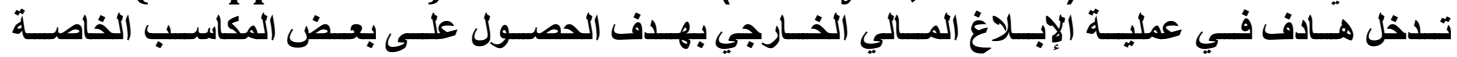

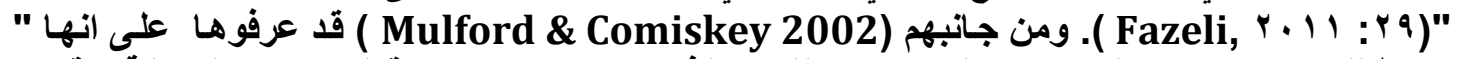
نشـاط للتلاعب بالإربـاح لتحقيق هدف محدد سلفا ، والذي يمكن تحديده من قبل الإدارة ، لمقابلة توقعات

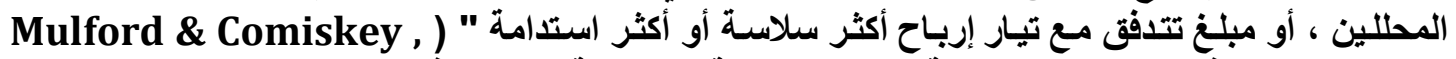

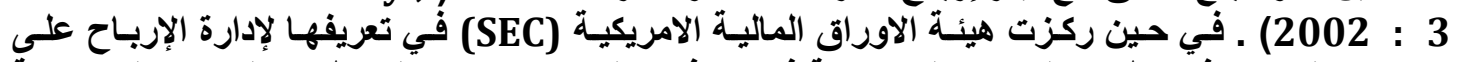

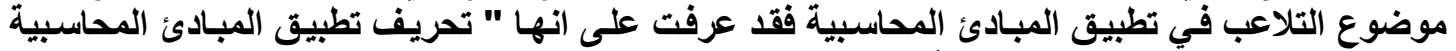

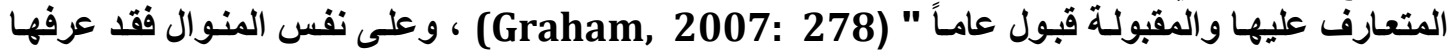
(Guan and others 2008 )

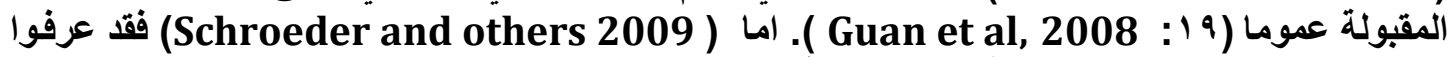

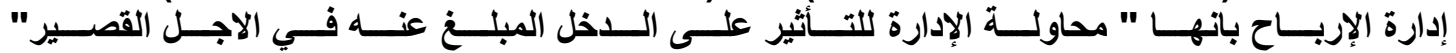

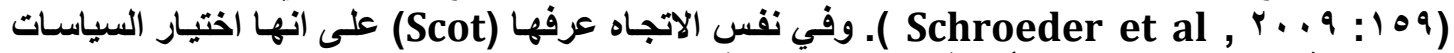

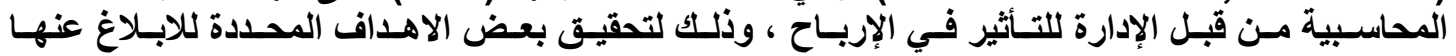


في حين اختزل (Kieso and others 2010) تعريفه لإدارة الإربـاح بممارسـات تمهيد الدخل

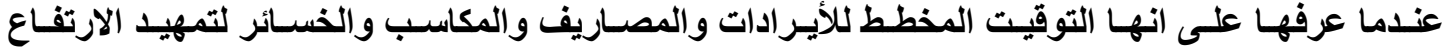

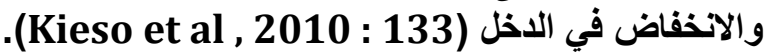

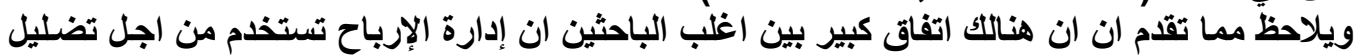

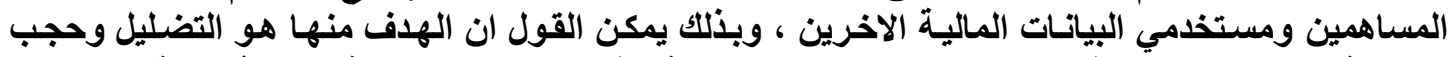

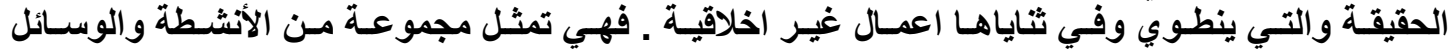

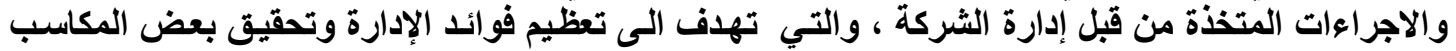

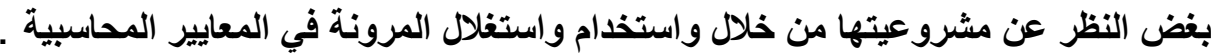

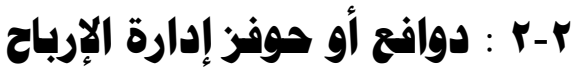

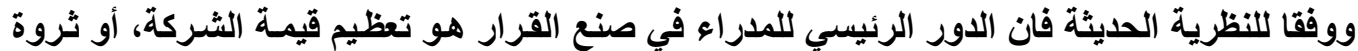

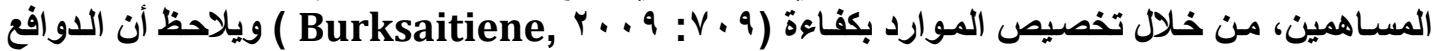

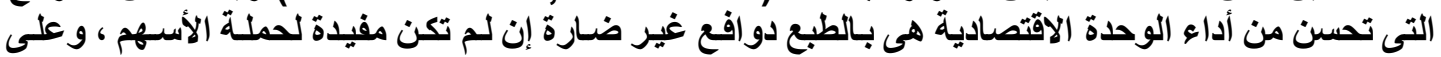

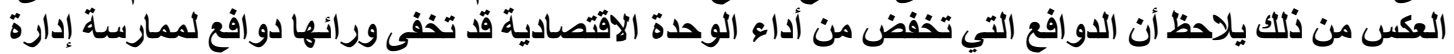

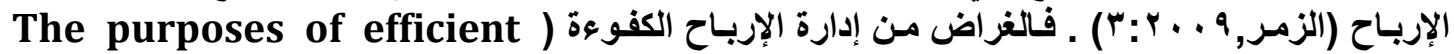

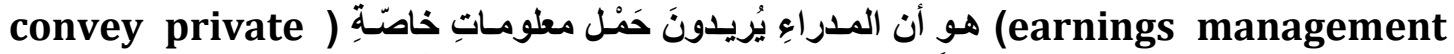

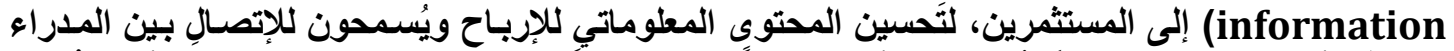

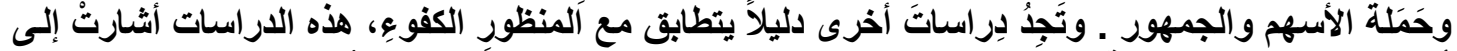

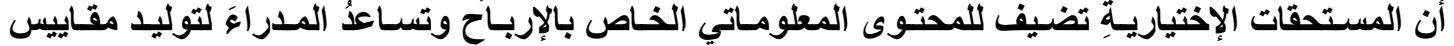

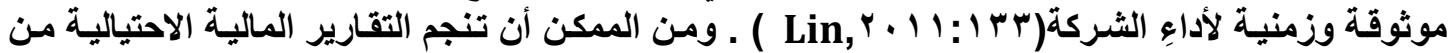

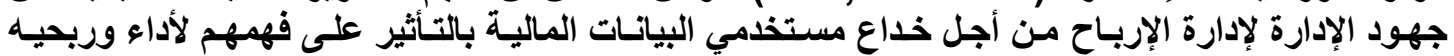

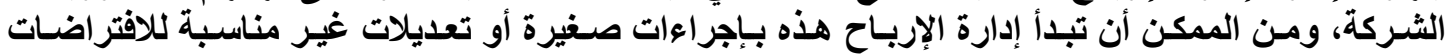

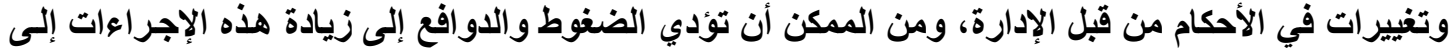

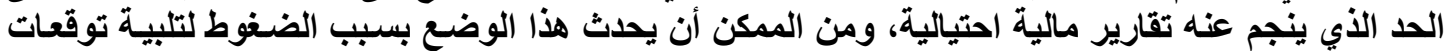

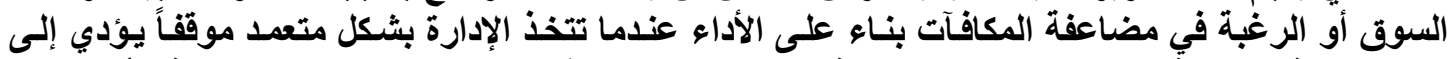

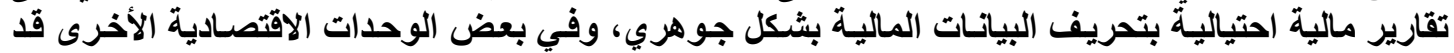
يتوفر دافع للإدارة لتخفيض الإرباح بمبلغ كبير لتخفيض الضريبة (ISA 240,2004:272) .

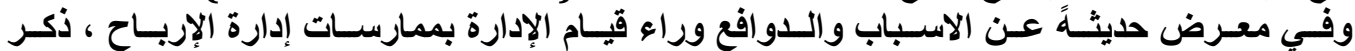

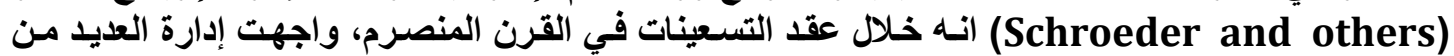

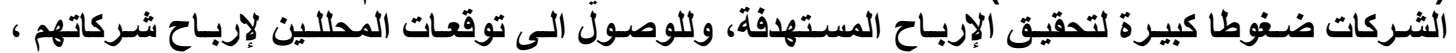

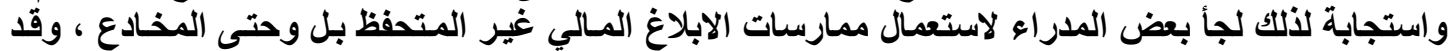

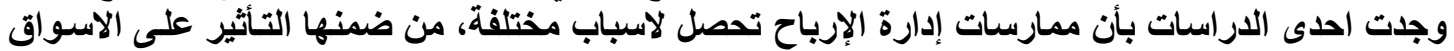

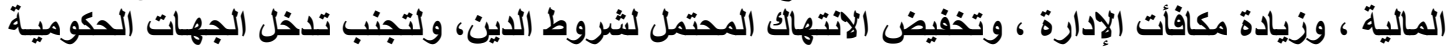

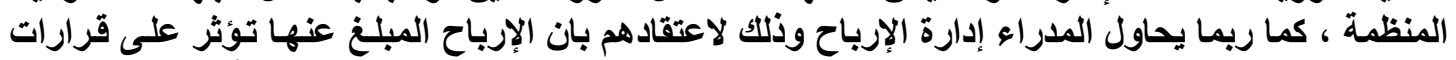

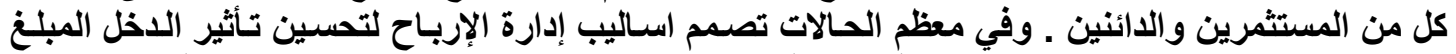

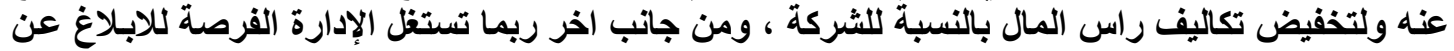

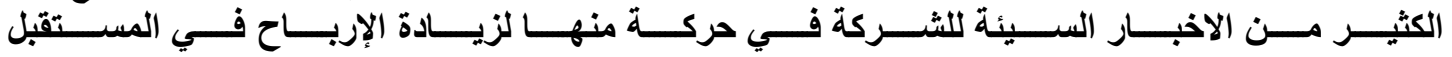




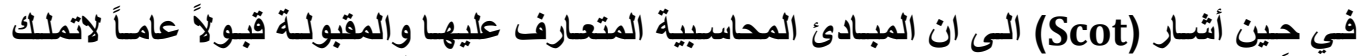

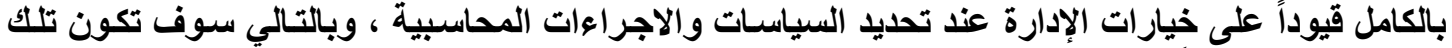

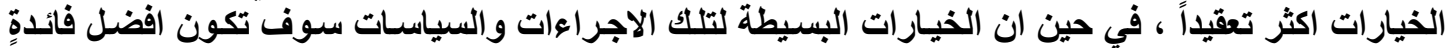

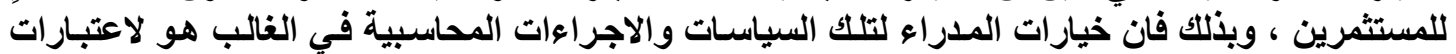

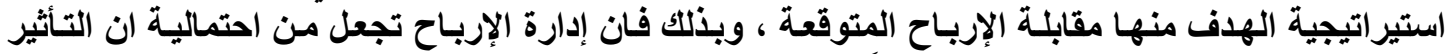
على الاخل الحقيقي ينبغي ان لايكون حقيقياً (427:

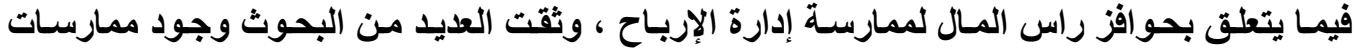

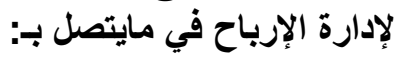

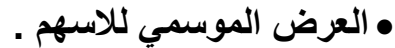

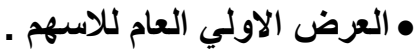

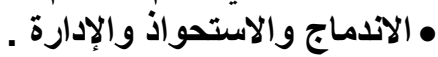

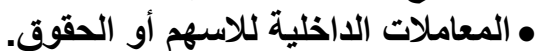

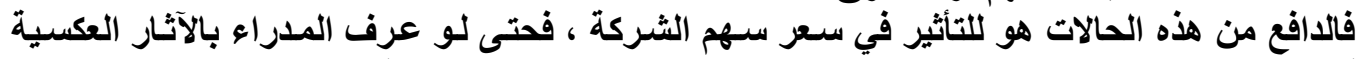

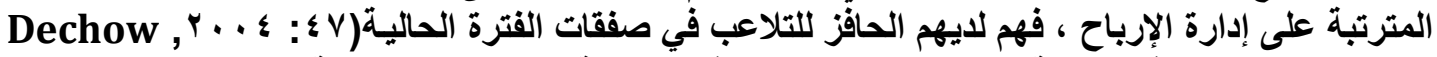

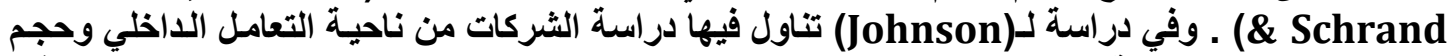

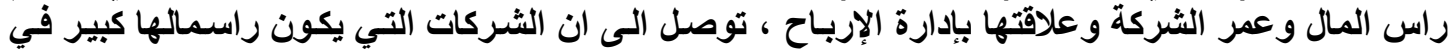

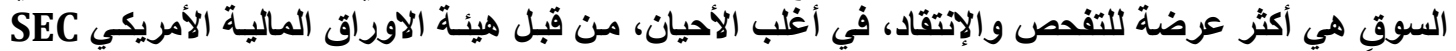

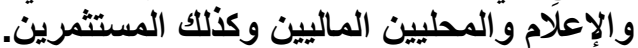

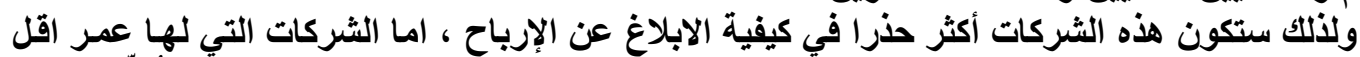

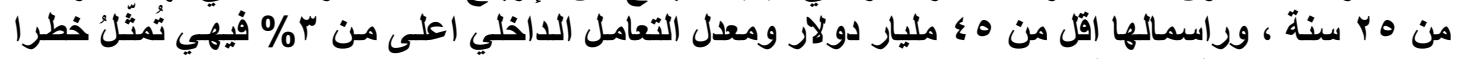

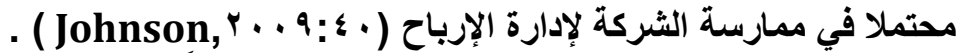

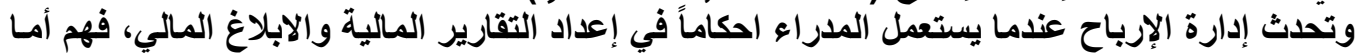

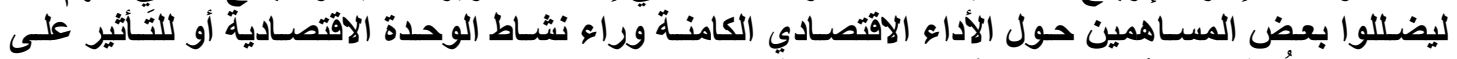

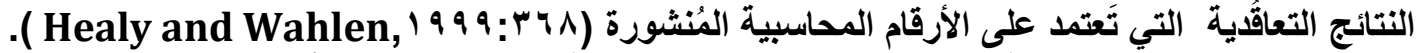

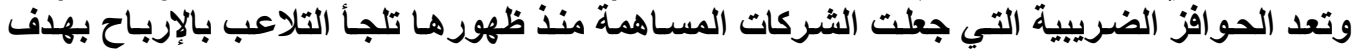

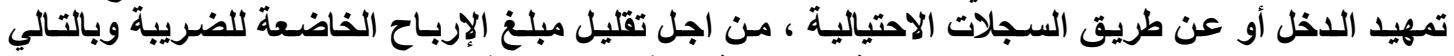

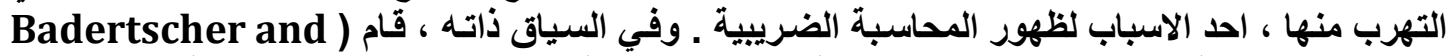
(others

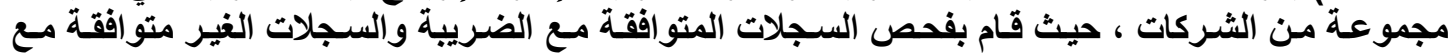

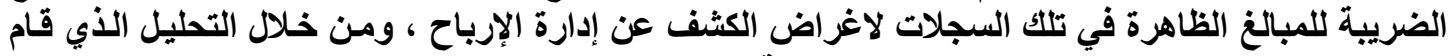

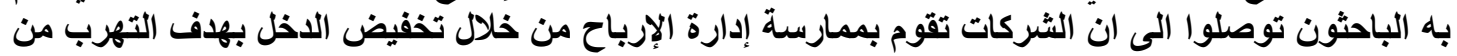

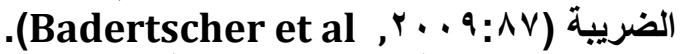
وفقا لفرضية التكاليف السياسية (political costs)، ان الثركات الكبيرة هي أكثر احتمـالا لاستخدام

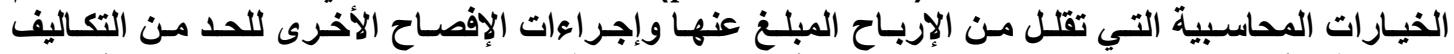

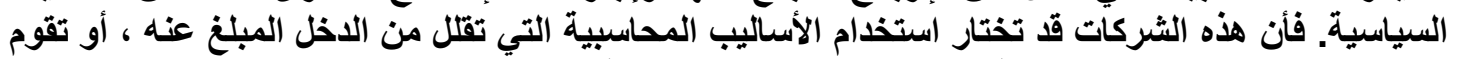

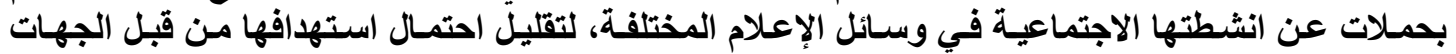

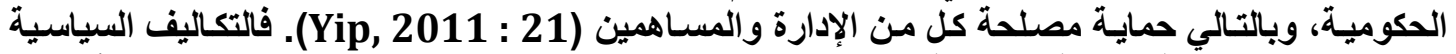

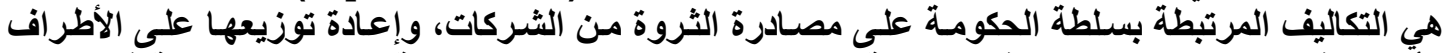

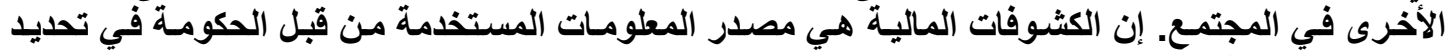




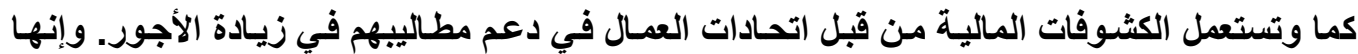

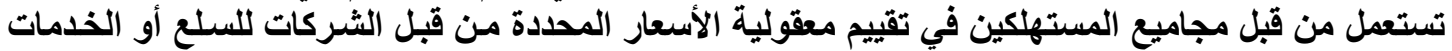

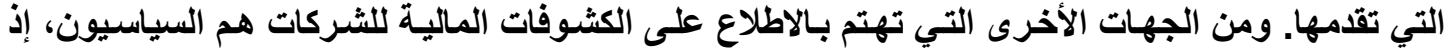

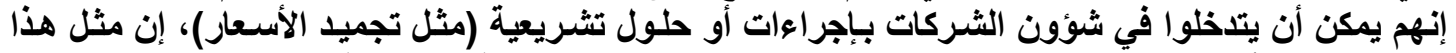

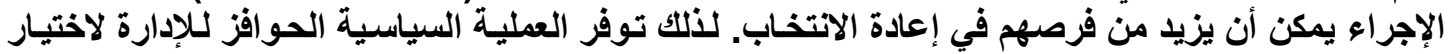

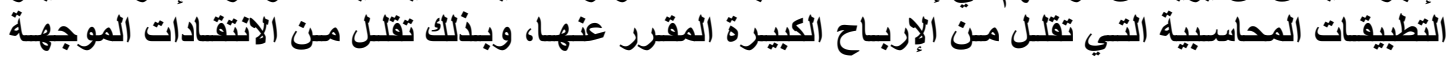

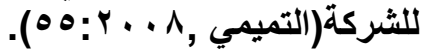

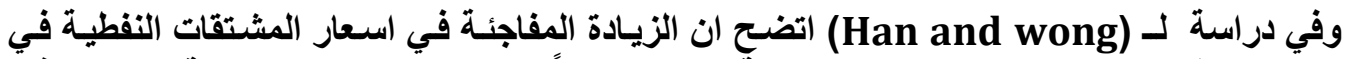

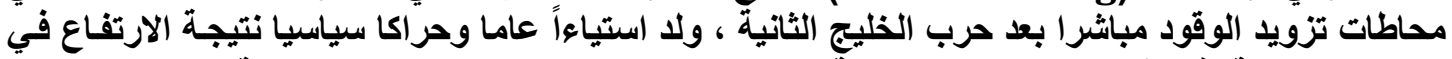

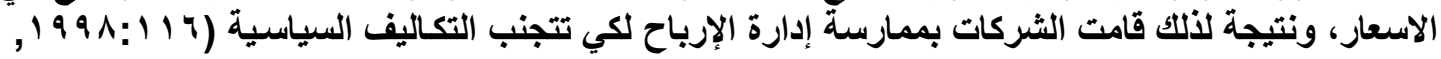

وفي دراسـة لـــ (Defond \& Jiambalvo, 1994) وجدوا بـان الثركات المختارة في الدراسـة

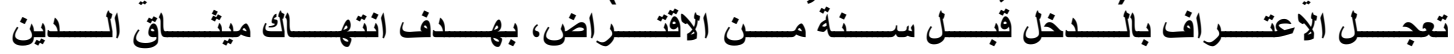
(ovenant Lending)

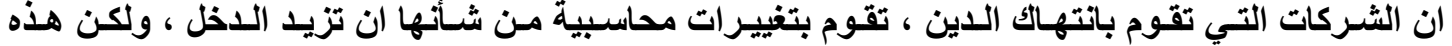

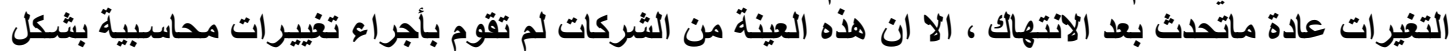

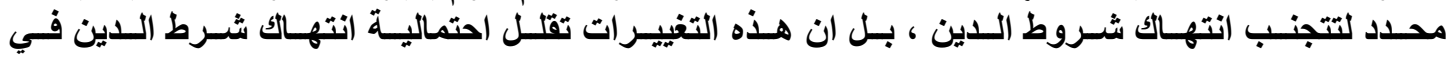

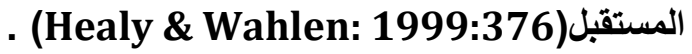
ويرى (Johnson) ان السبب الرئيسي لإدارة الإرباح يتمثل بالحوافز الممنوحة للإدارة والمستندة

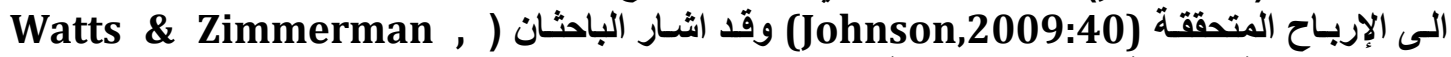

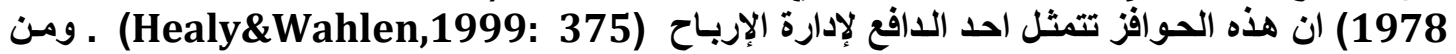

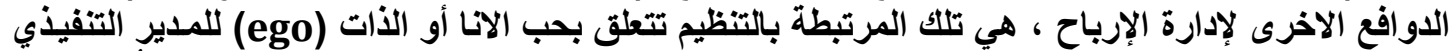

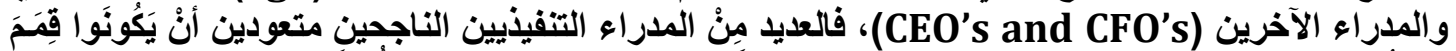

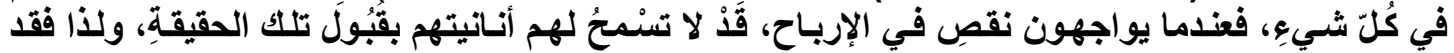

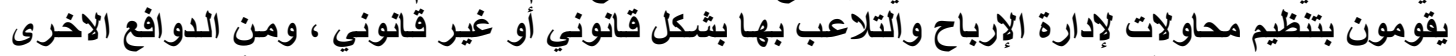

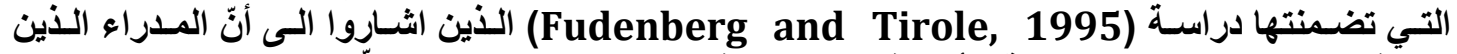
يتخوفون على مواقعهم الوظيفية ، أو الذين يَعْملون في الصناعاتِ الثديدة التقّلب )

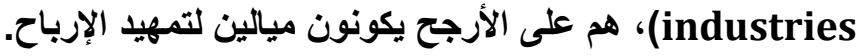

r r r r الساليب إدارة الإرباح

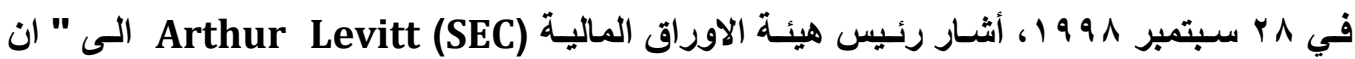

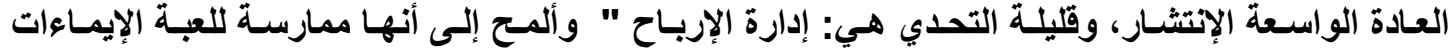

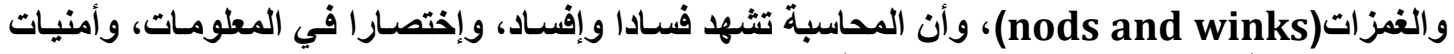
كثيرة غير منفذة. والتي لم تنجح السي اليوم في إعطاء تمثيل دقيق وصحيح (

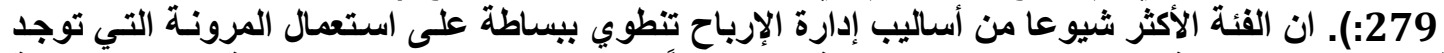

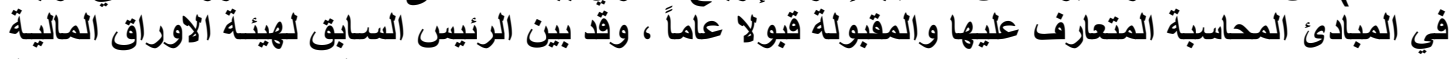

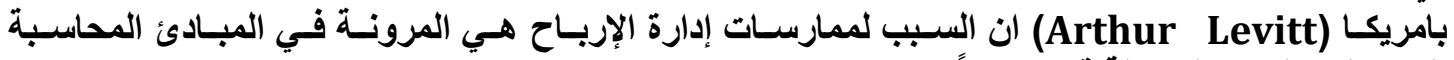

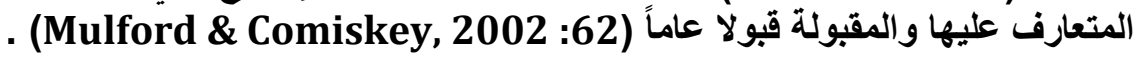




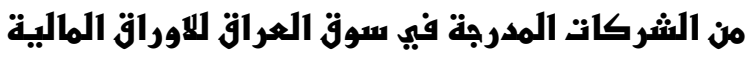

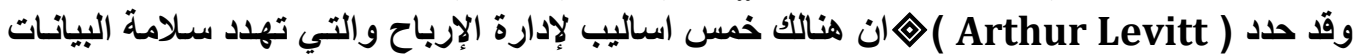

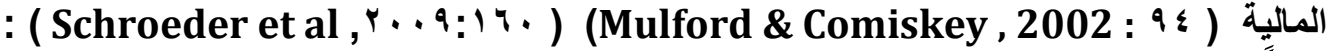

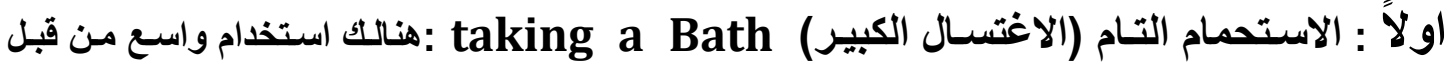

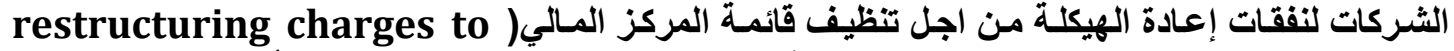

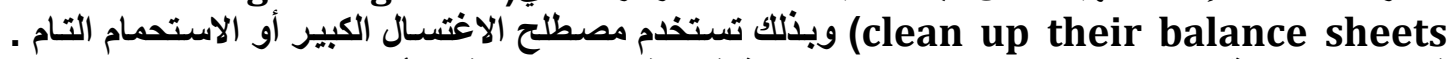

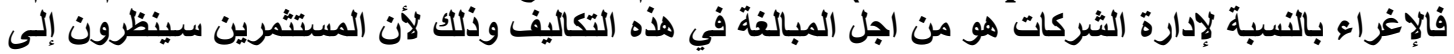
ما بعد الخسارة لمرة واحدة ويركزون فقط على الإرباح المستقبلية ( :

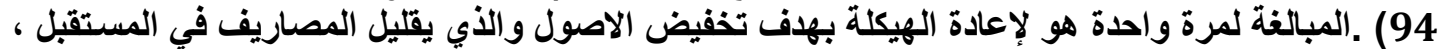

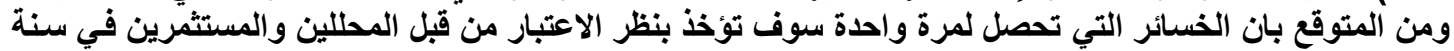

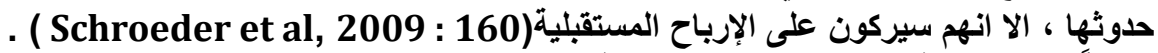

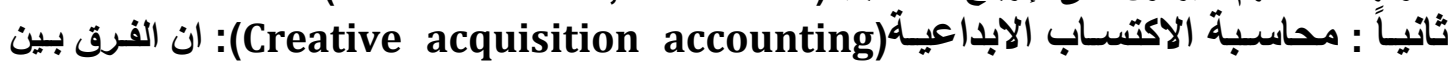

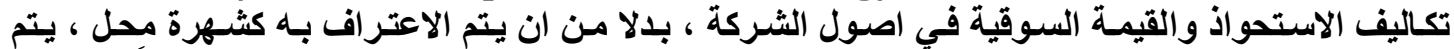

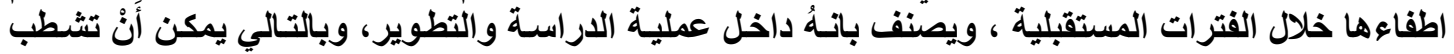

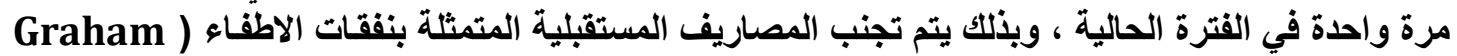

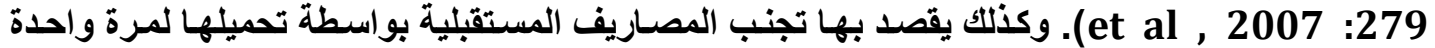

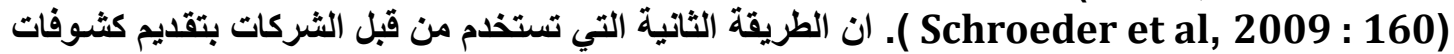

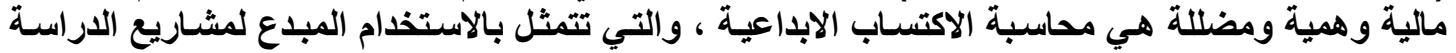

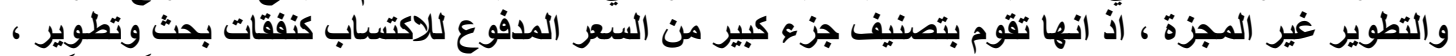

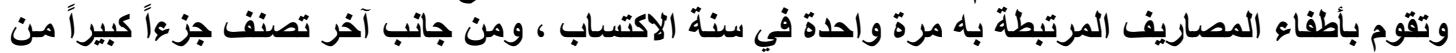

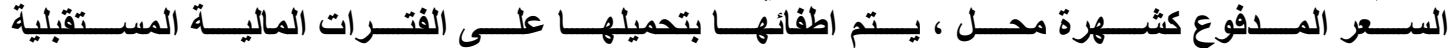

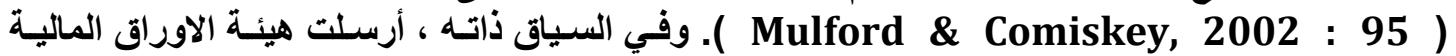

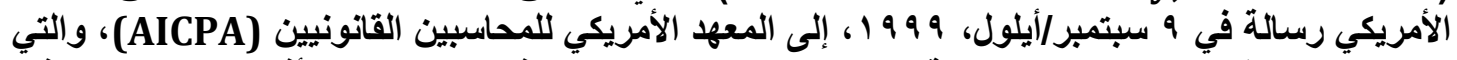

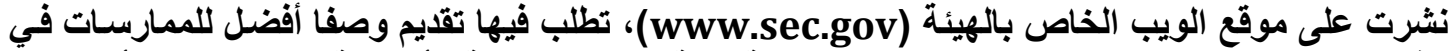

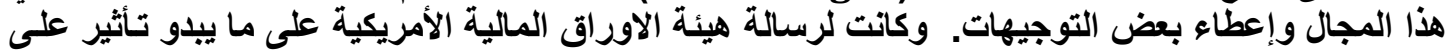

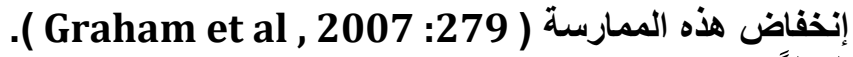

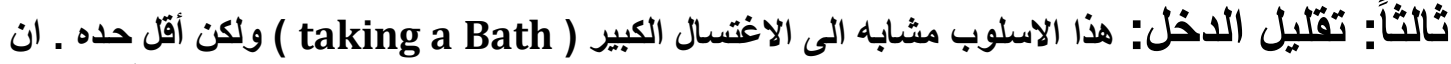

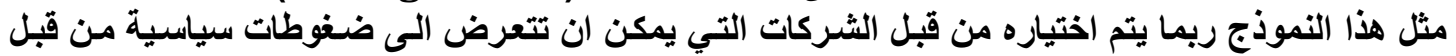

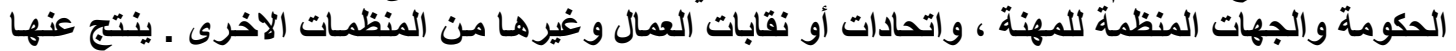

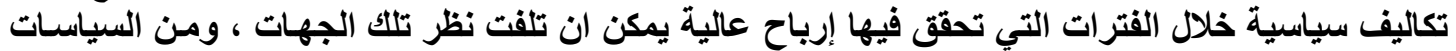

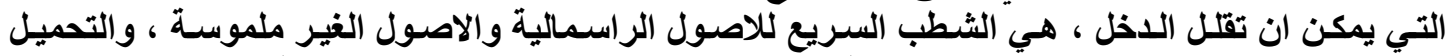

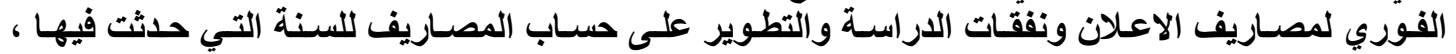

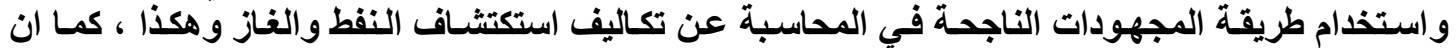

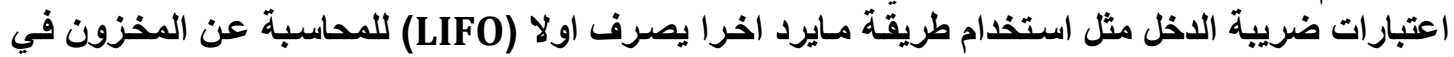

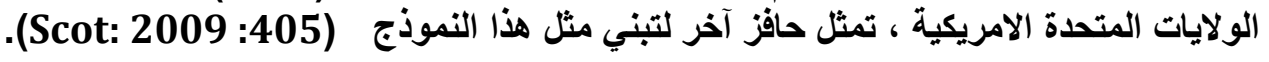

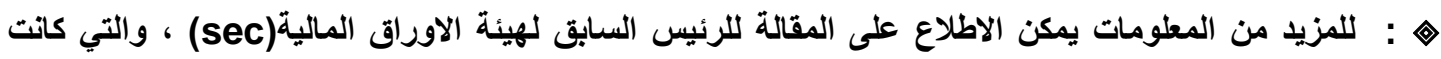

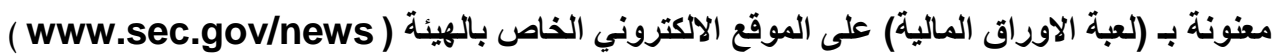


رابعاً: تمهيد الاخل :عرف (Balkaoui) تمهيد الاخل على انه التطيف المتعد أو المقصود للتقلبات

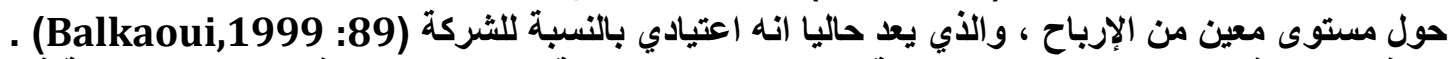

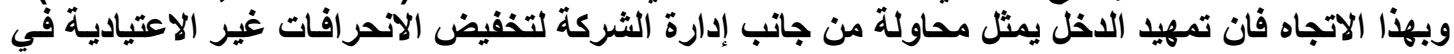

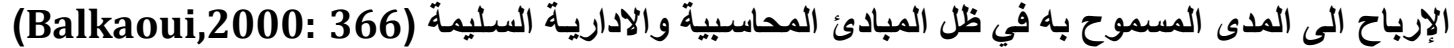

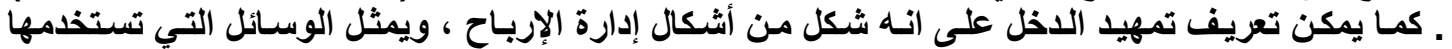

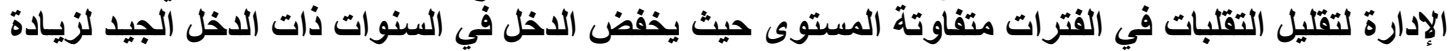

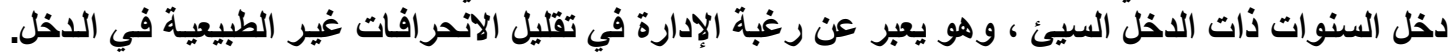

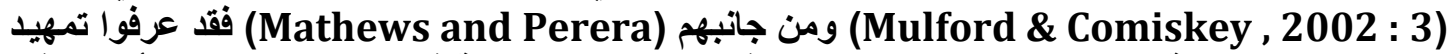

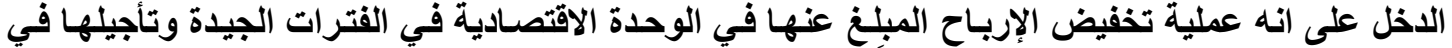

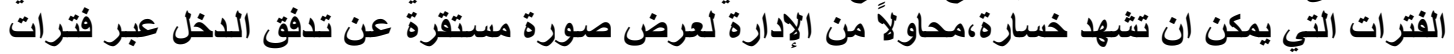
(Mathews and Perera, 1991: 234) وترد عدد من الدوافع للتمهيد في الادبيات المحاسبية ، مثل (90: Balkaoui,1999):

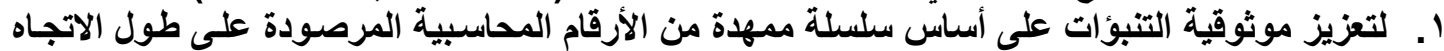

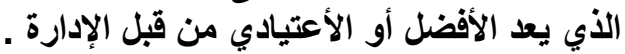

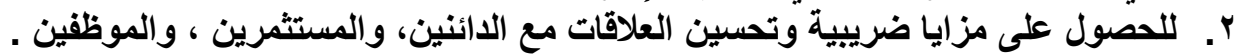

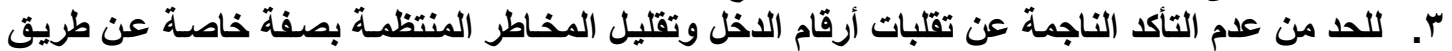

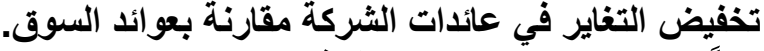

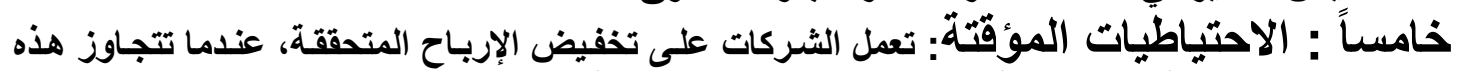

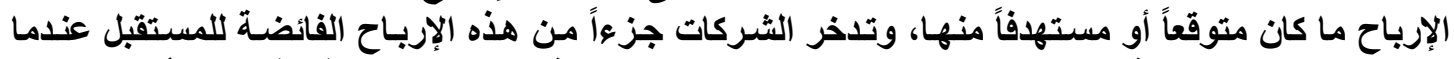

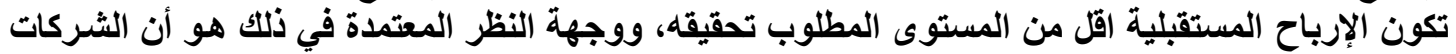

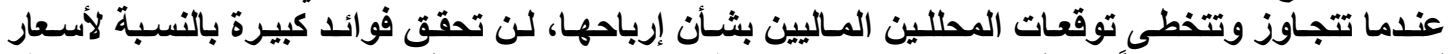

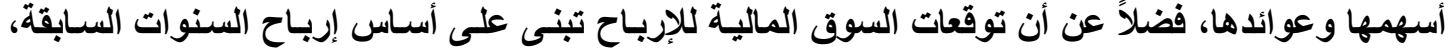

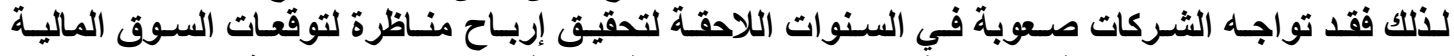

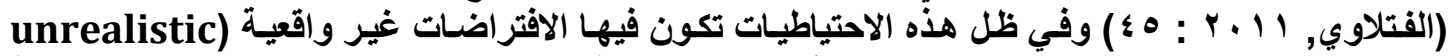

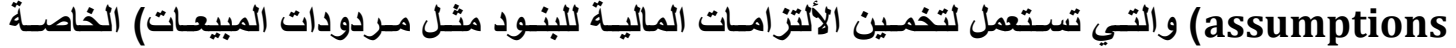
بالضـمان ، وخسـائر القروض والفي وتكـاليف الضـمان (279:

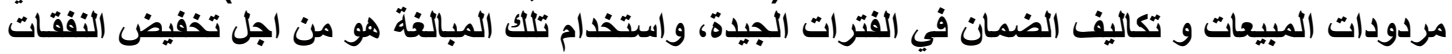

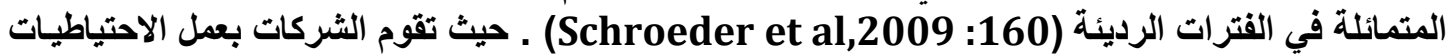

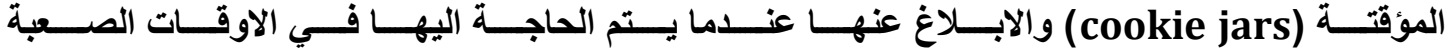
(Graham et al , $2007: 279$ )

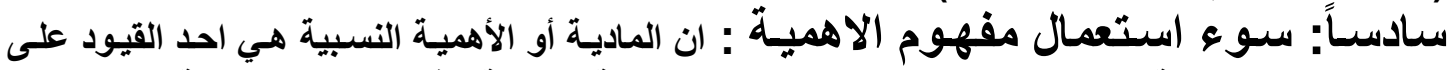

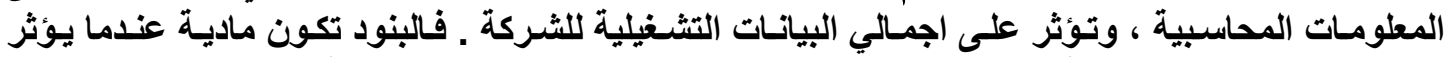

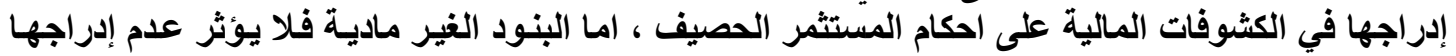

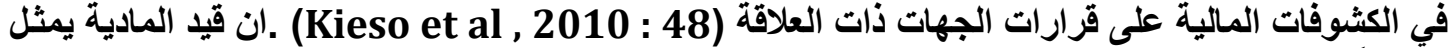

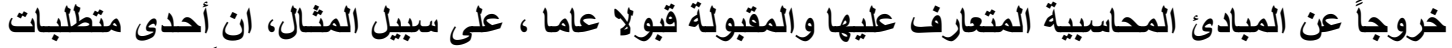

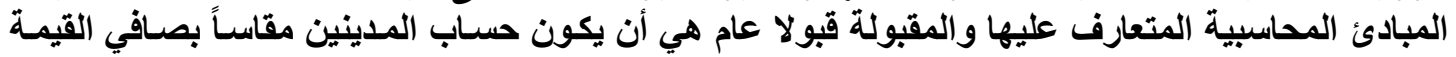
القابلــة للتحقــق (Set Realizable Value) 


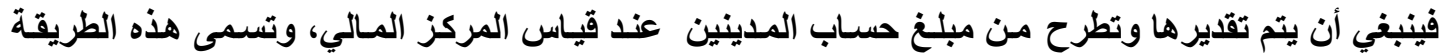

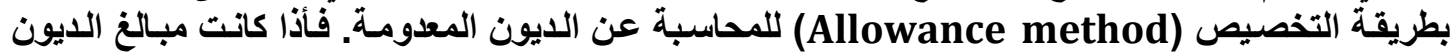

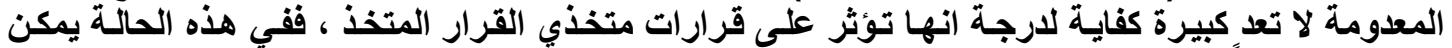

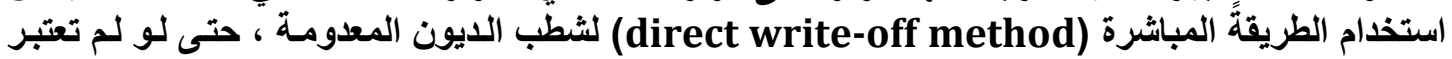

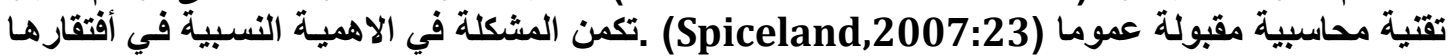

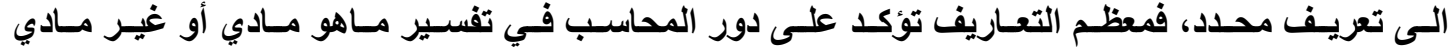

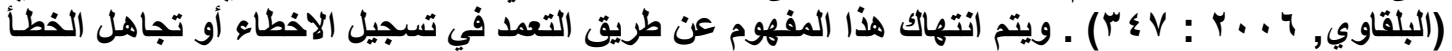

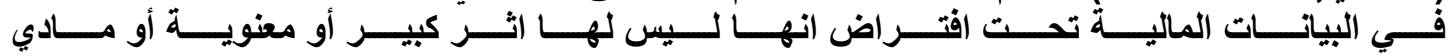

.(Schroeder et al, 2009: 160)

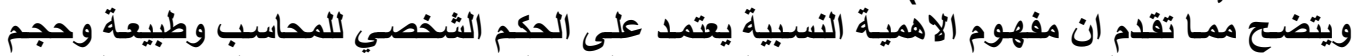

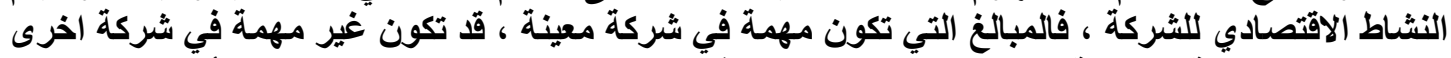

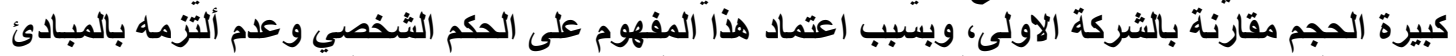

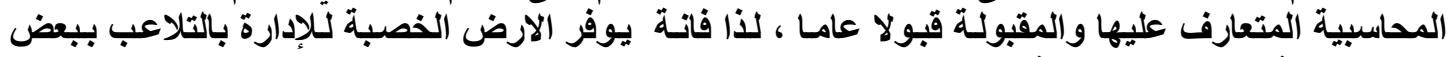

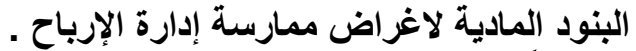

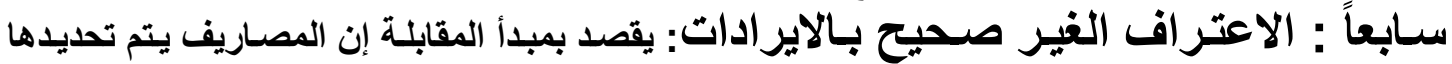

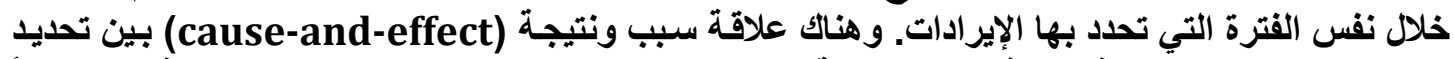

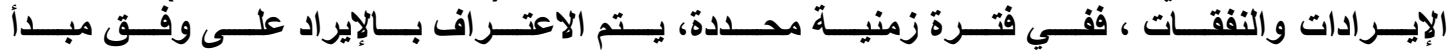

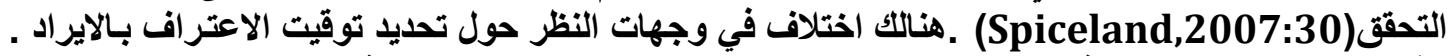

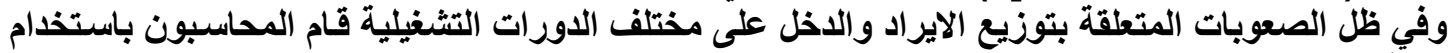

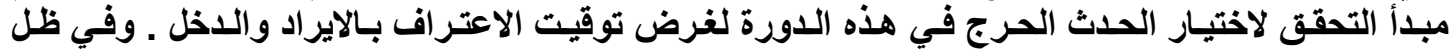

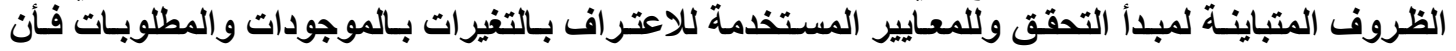

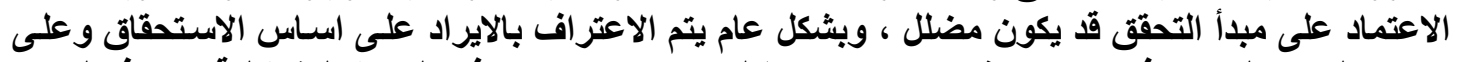

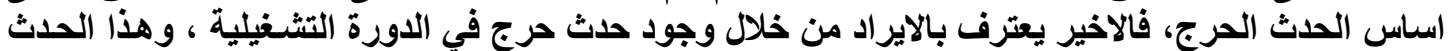

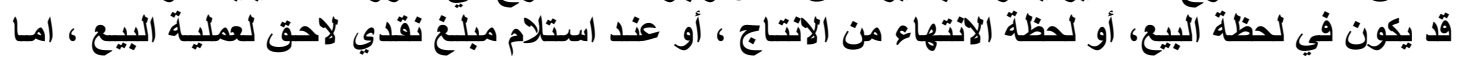

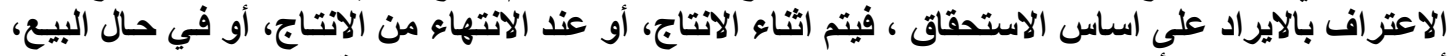

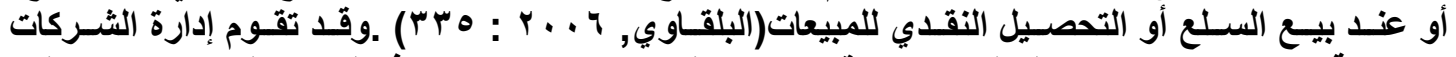

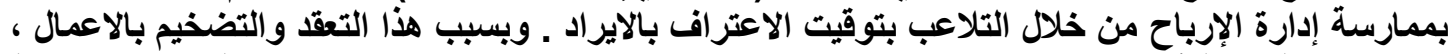

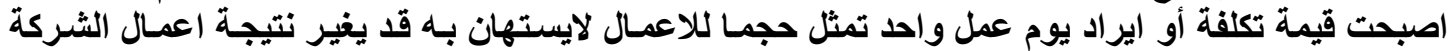

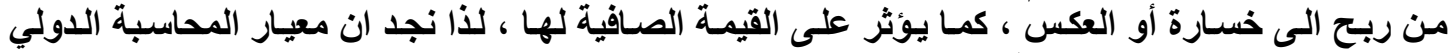

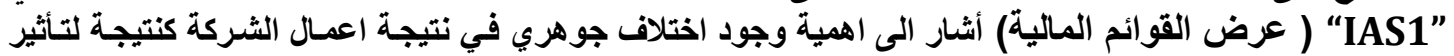

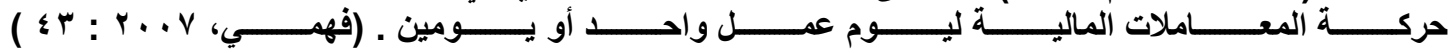
وتضيف ( Dechow \& Schrand ) الاسلوبين التاليين لإدارة الإرباح :

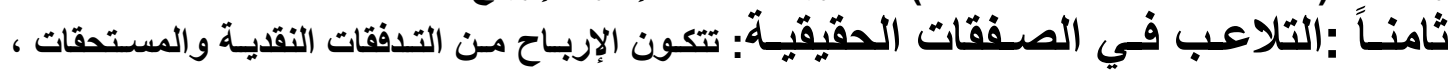

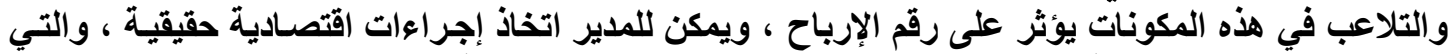

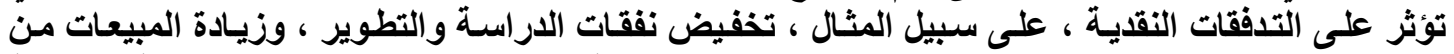

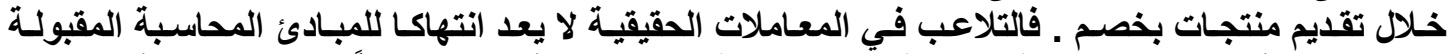

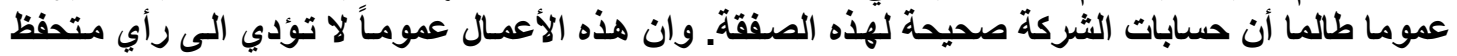

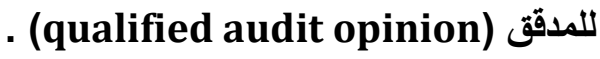


وعلى الرغم من ذلك ، ان مثل هذه الأعمال يمكن ان تنطوي على ثأثير كبير على جودة الإربـاح ، وثثأثيرات

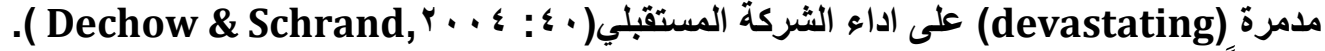

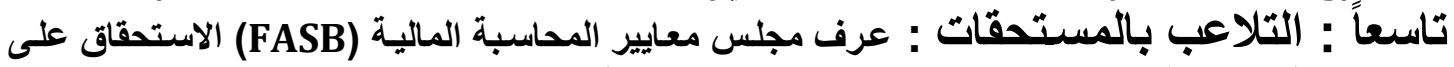

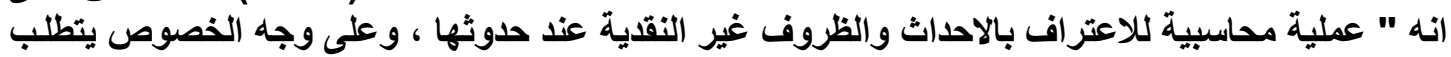

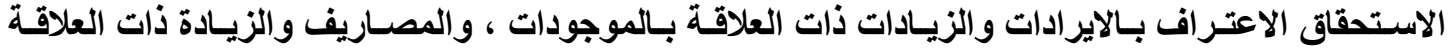

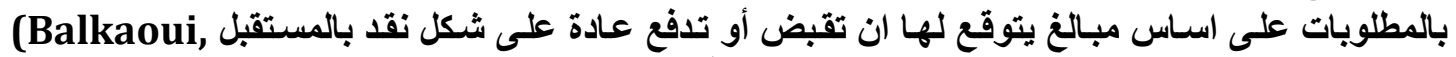

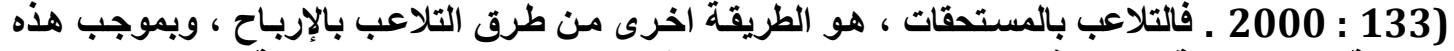

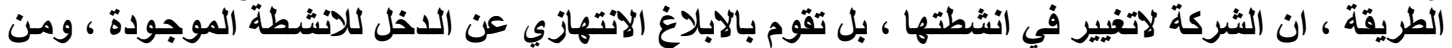

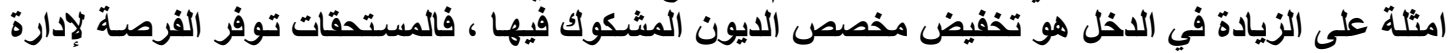

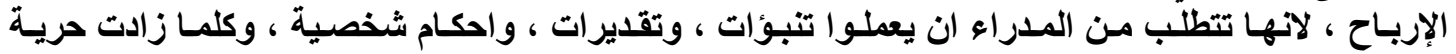

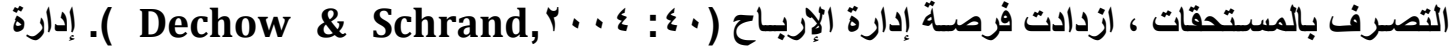

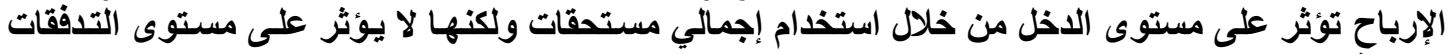

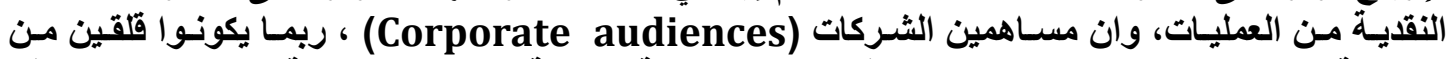

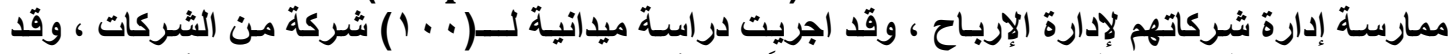

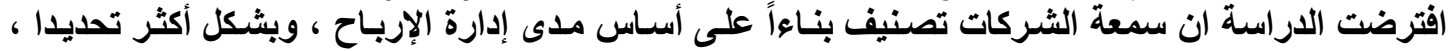

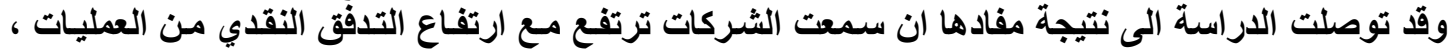

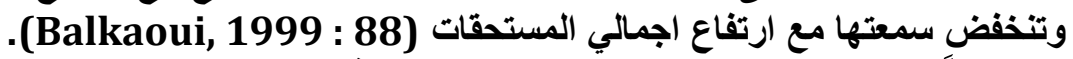

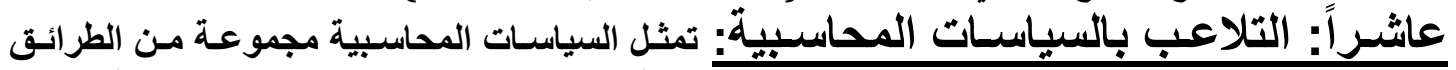

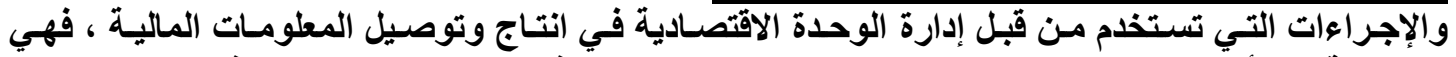

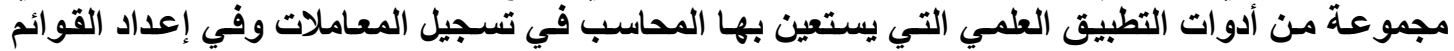

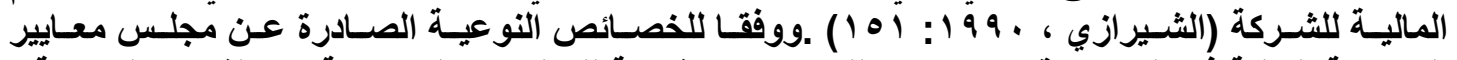

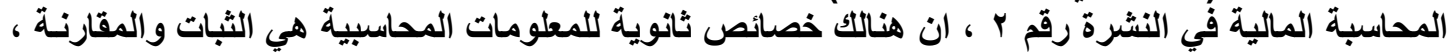

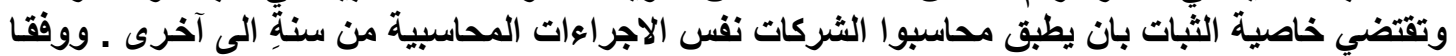

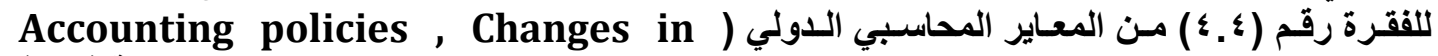
يسمح بتغيير السياسـات المحاسبية فقط في (Accounting, Estimates and Errors "IAS8"

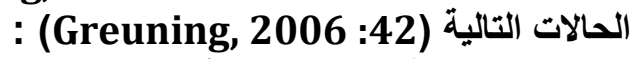

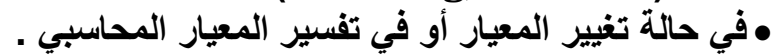

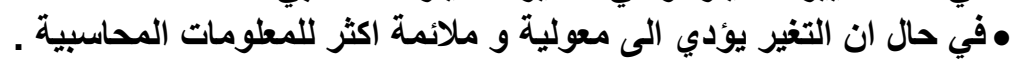

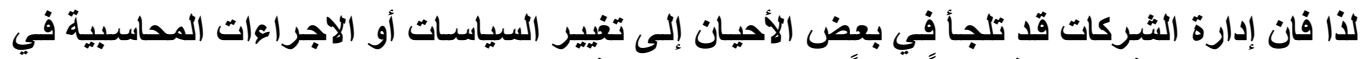

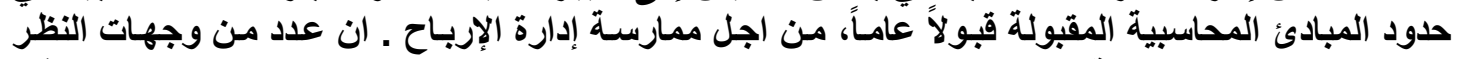

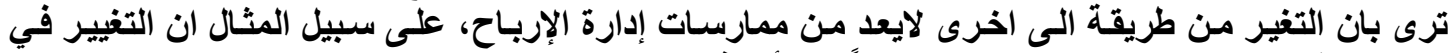

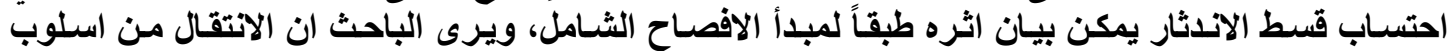

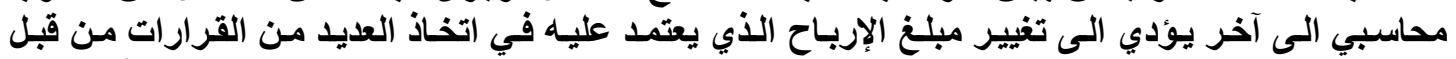

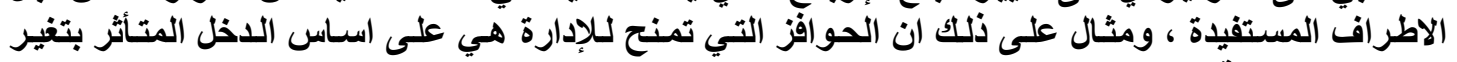

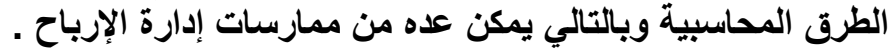




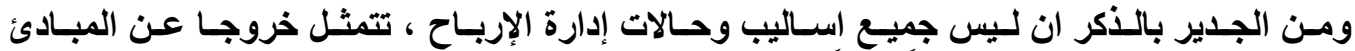

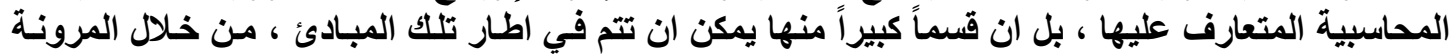

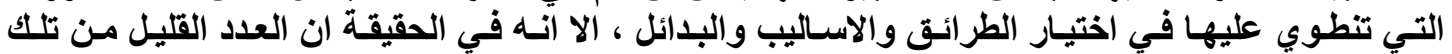

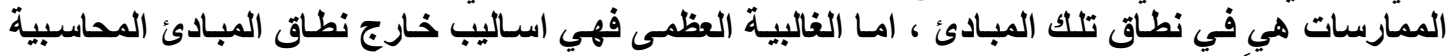

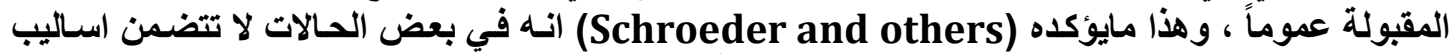

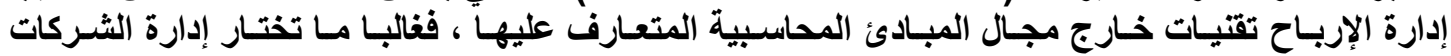

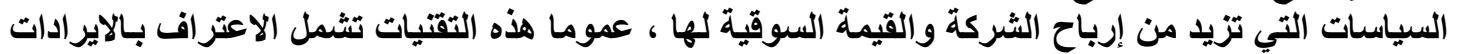

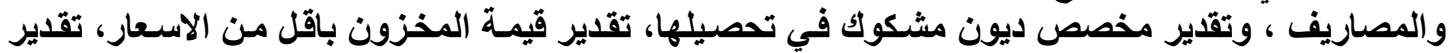

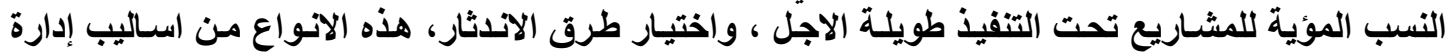

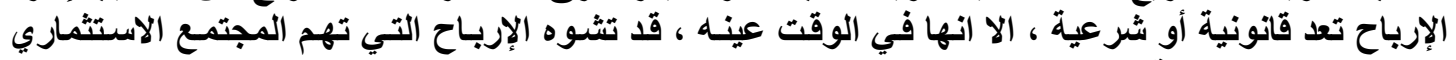

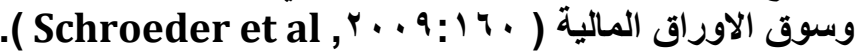

الهور الثالث/ استخدام قانون بنفورد في الماسبة والتدقيق ودوره في الكشف

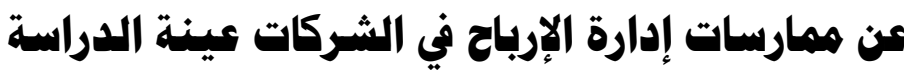

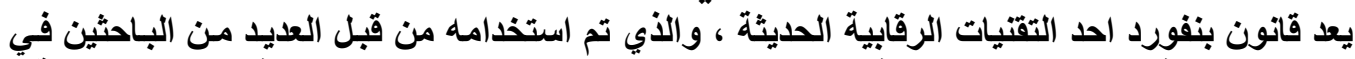

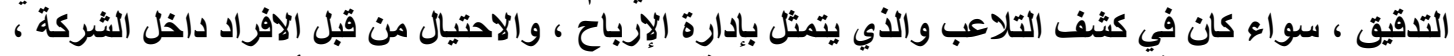

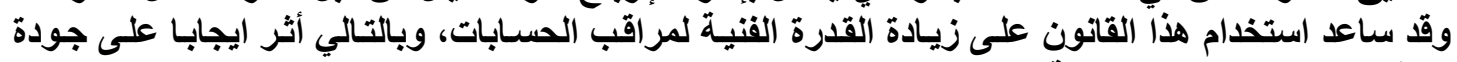

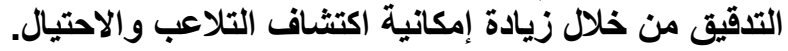

\section{r-1 : نبذة تهريفية عن قانهون بنفورد}

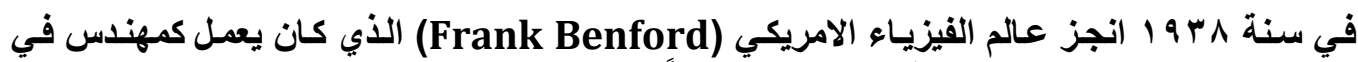

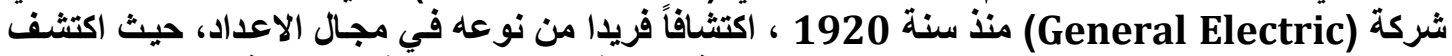

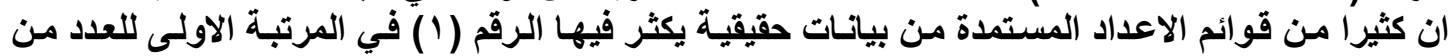

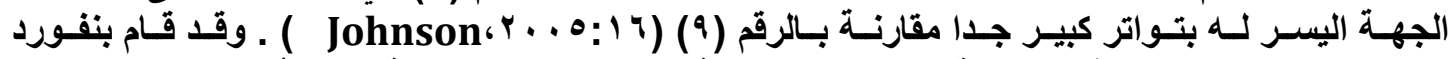

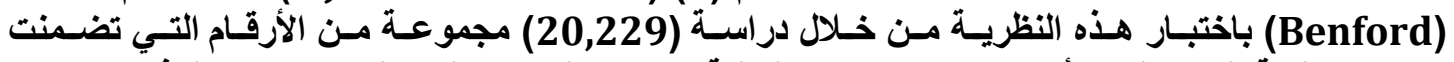

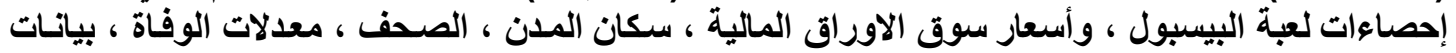

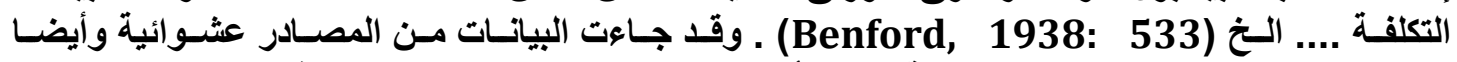

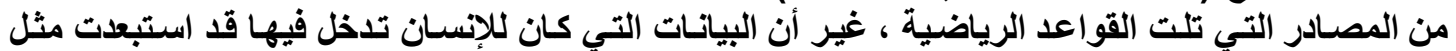

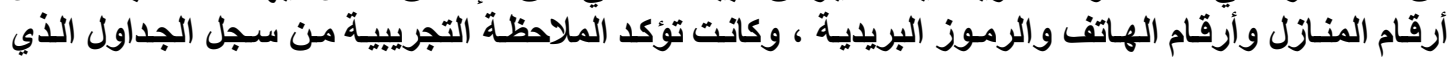

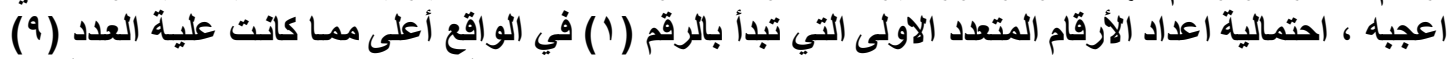

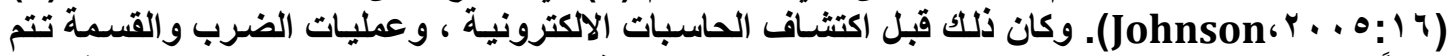

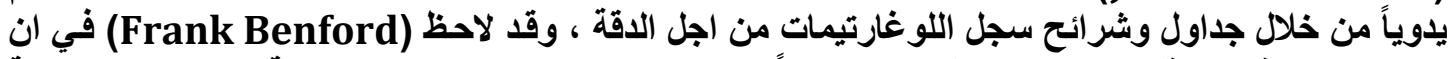

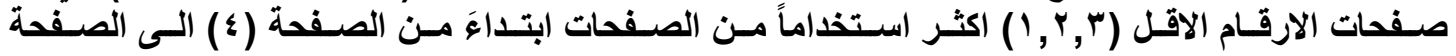
. (Johnson,2005:16)(9) 
لقد اكتثف هذا القانون في بادئ الامر من قبل العالم القلكي الامريكي (Simon Newcomb) عام

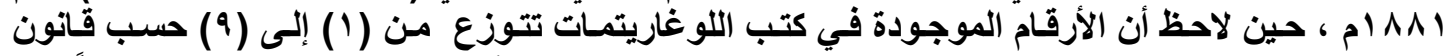

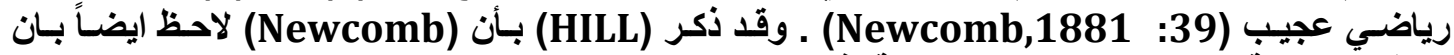

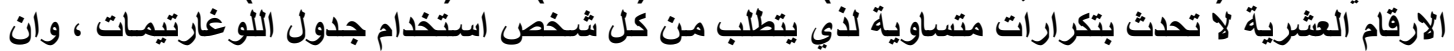

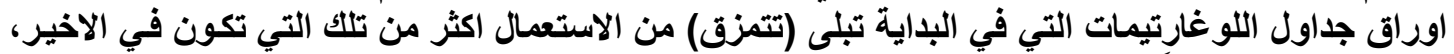

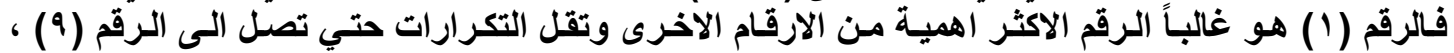

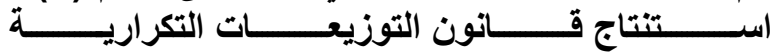

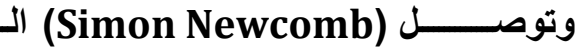

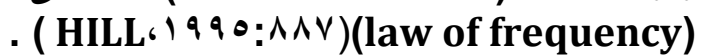

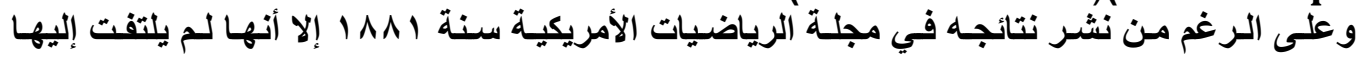

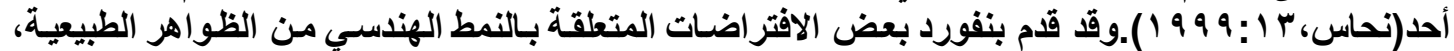

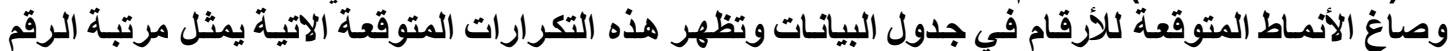

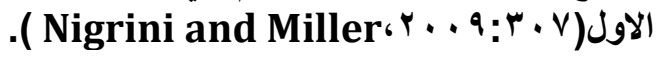

$$
\begin{aligned}
& \text { Prob }(\mathrm{D} 1=\mathrm{d} 1)=\log 10\left(1+\frac{1}{\mathrm{~d} 1}\right) ; \mathrm{d} 1 \in\{1,2, \ldots .9\} \\
& \text { Prob }(\mathrm{D} 2=\mathrm{d} 2)=\sum_{\mathrm{d}=9}^{9} \log 10\left(1+\frac{1}{\mathrm{~d} 2}\right) ; \mathrm{d} 2 \in\{0,1, \ldots .9\}
\end{aligned}
$$

Prob(D1D2 $=\mathrm{d} 1 \mathrm{~d} 2) \log 10\left(1+\frac{1}{\mathrm{~d} 1 \mathrm{~d} 2}\right) ; \mathrm{d} 1 \mathrm{~d} 2 \in\{10,11, \ldots .99\}$

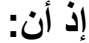

Pثثل احتمال حدوث المشاهدة : P

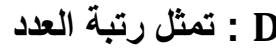

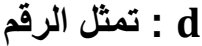

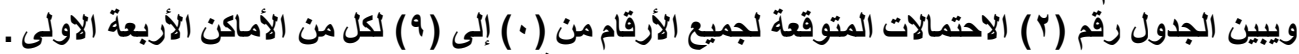

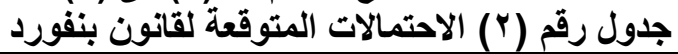

\begin{tabular}{|r|c|c|c|c|}
\hline \multicolumn{1}{|c|}{ D } & Digit First & $\begin{array}{c}\text { Digit } \\
\text { Second }\end{array}$ & $\begin{array}{c}\text { Digit } \\
\text { Third }\end{array}$ & $\begin{array}{c}\text { Digit } \\
\text { Fourth }\end{array}$ \\
\hline 0 & & .11968 & .10178 & .10018 \\
\hline 1 & .30103 & .11389 & .10138 & .10014 \\
\hline 2 & .17609 & .10882 & .10097 & .10010 \\
\hline 3 & .12494 & .10433 & .10057 & .10006 \\
\hline 4 & .09691 & .10031 & .10018 & .10002 \\
\hline 5 & .07918 & .09668 & .09979 & .09998 \\
\hline 6 & .06695 & .09337 & .09940 & .09994 \\
\hline 7 & .05799 & .09035 & .09902 & .09990 \\
\hline 8 & .05115 & .08757 & .09864 & .09986 \\
\hline 9 & .04576 & .08500 & .09827 & .09982 \\
\hline
\end{tabular}

( Nigrini \&. Wells، $r+1 ~ r: 0$ ) 


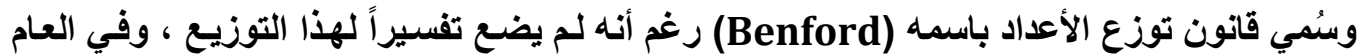

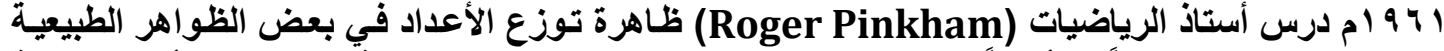

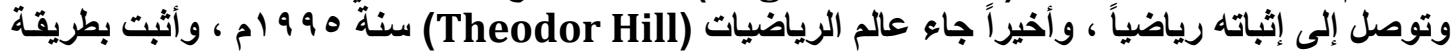

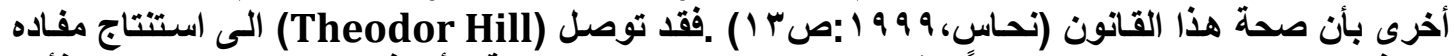

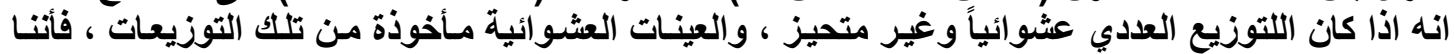

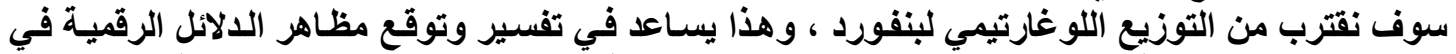
مختلف التجارب العملية ، ويساعد في تحقيق التطبيقات الحديثة التئي لتحاسوب ،

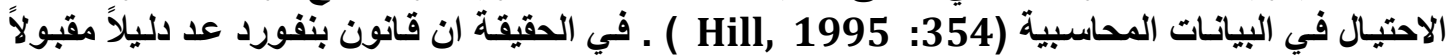

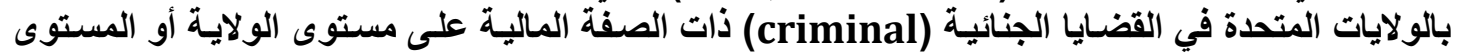

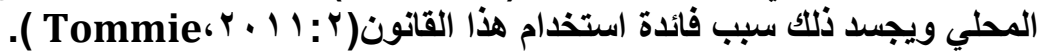

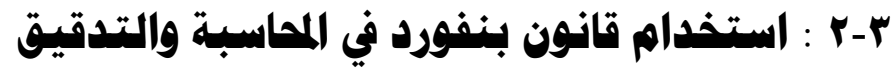

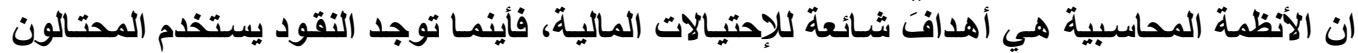

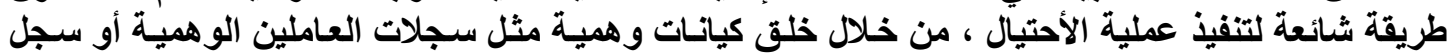

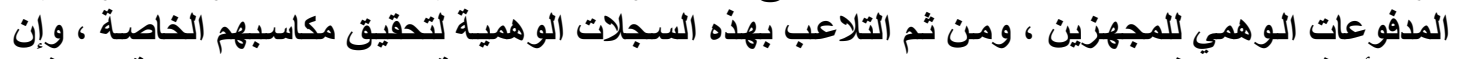

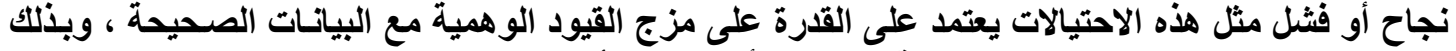

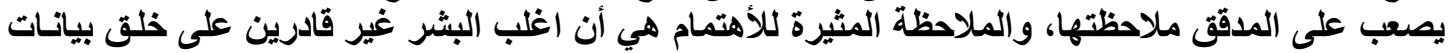

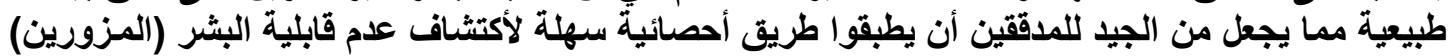

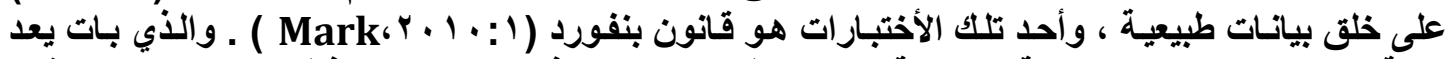

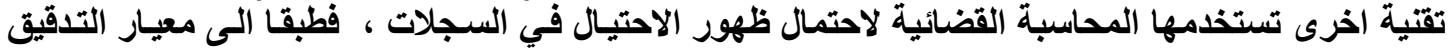

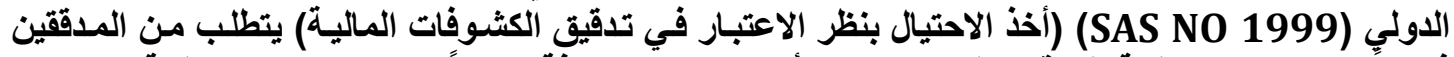

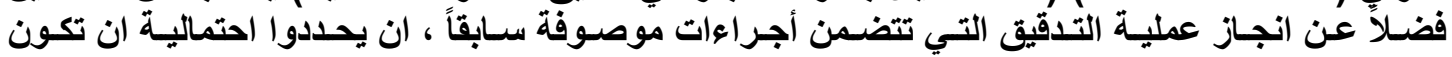

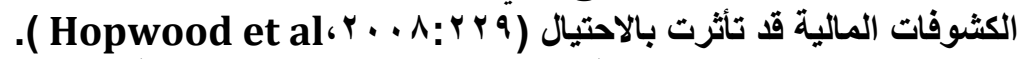

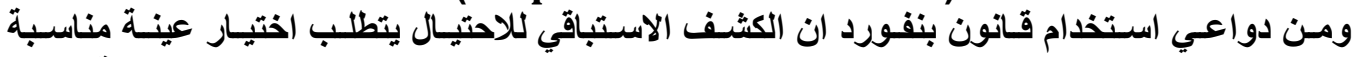

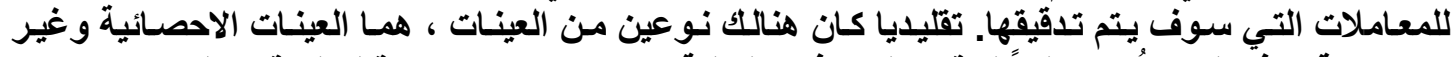

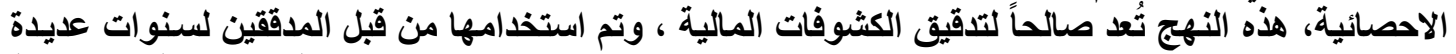

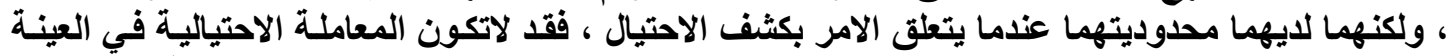

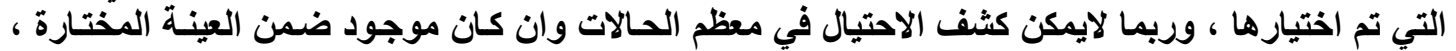

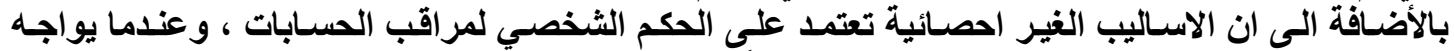

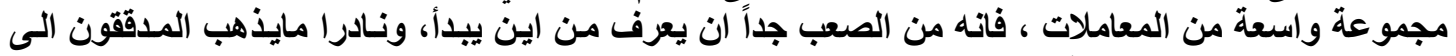

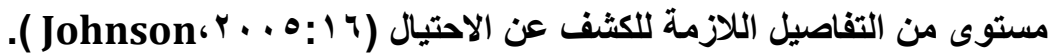

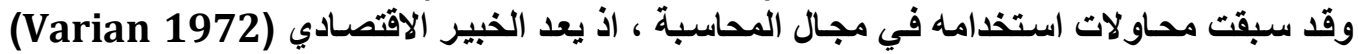

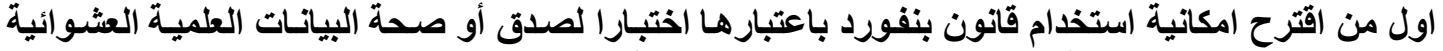

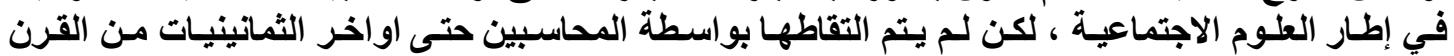

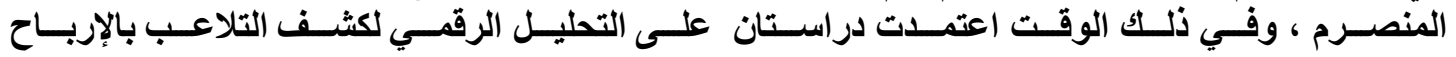




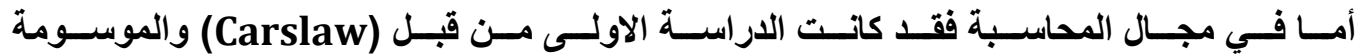
'(Anomalies in Income Numbers: Evidence of Goal Oriented Behavior)-

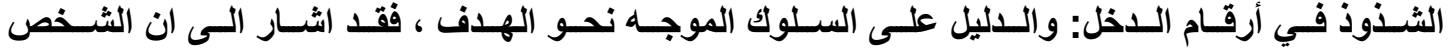

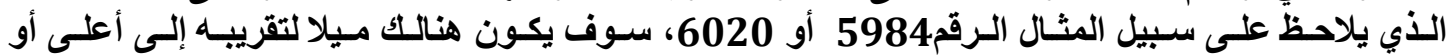

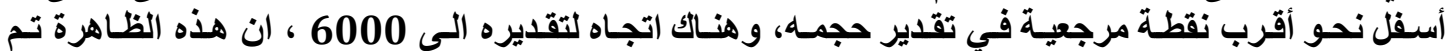

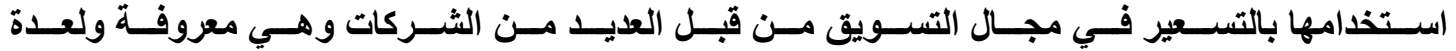

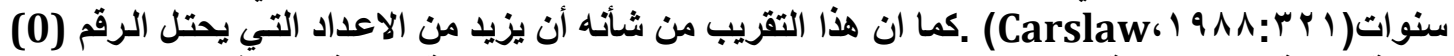

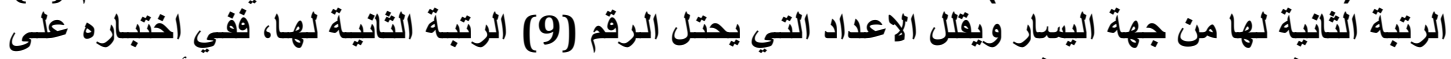

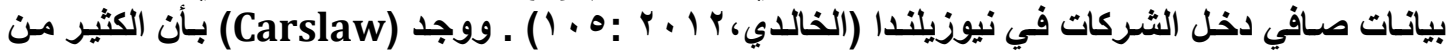

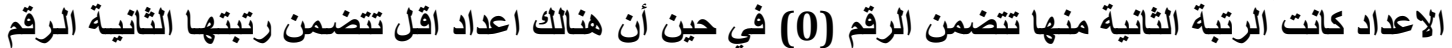

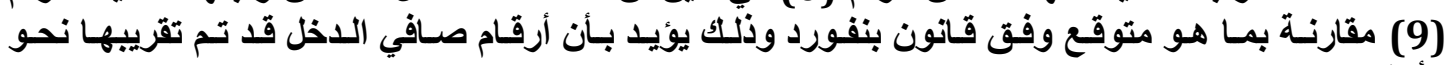

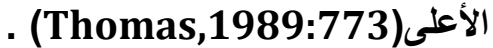

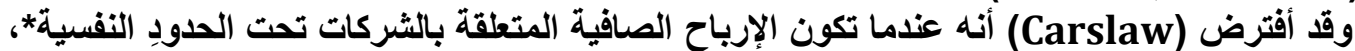

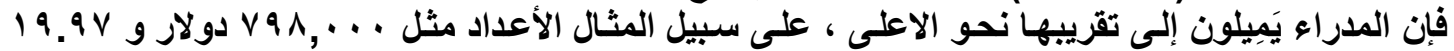

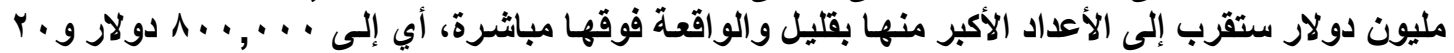

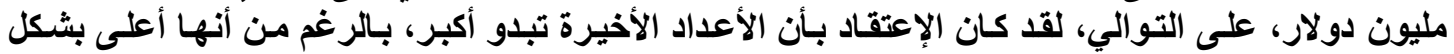

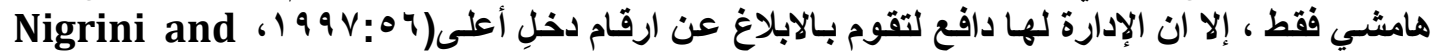

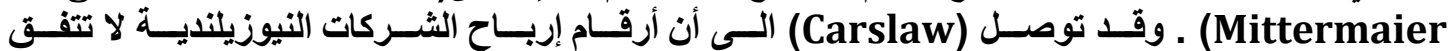

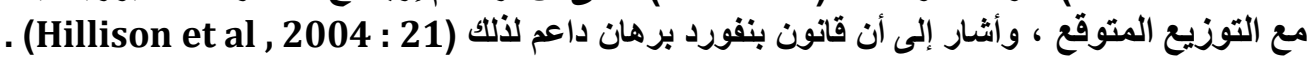

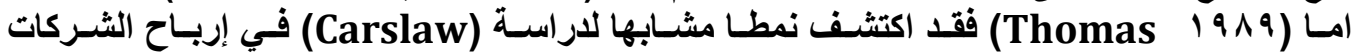

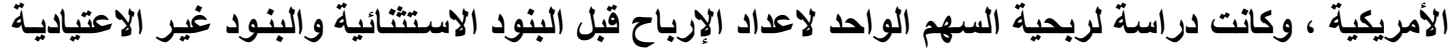

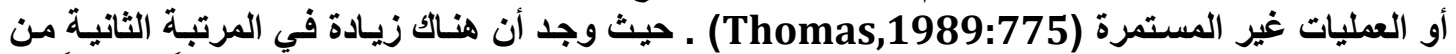

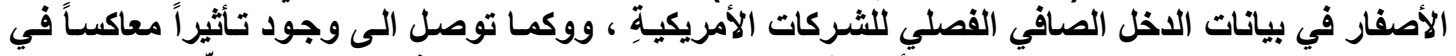

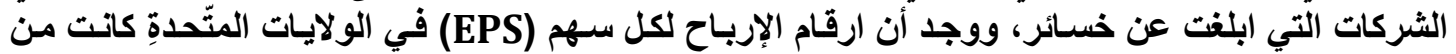

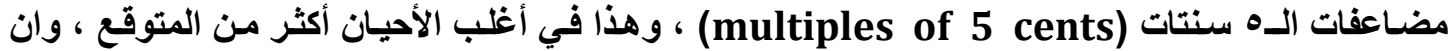

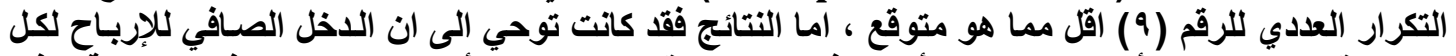

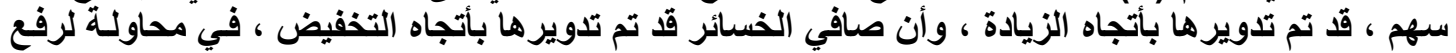

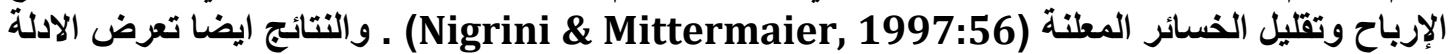

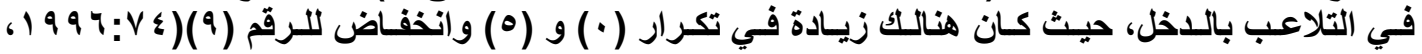

(Nigrini

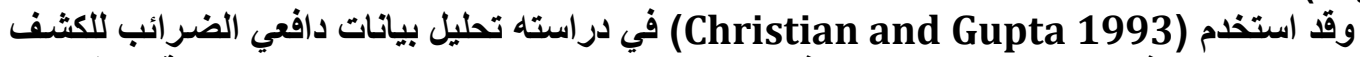

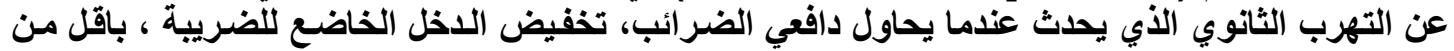

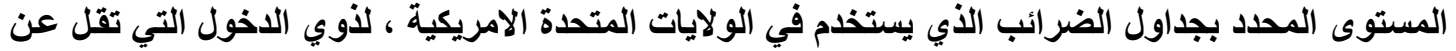

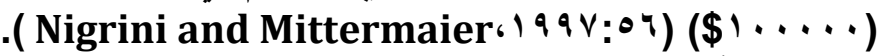
وقد أشار (Nillison et al) الى ان (Nini) يبذو هو الباحث الاول الذي استخدم قانون بنفورد

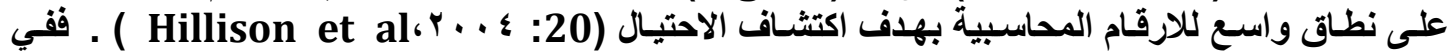

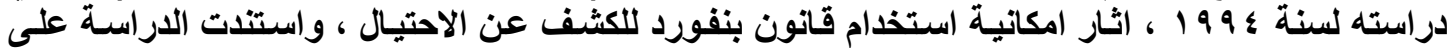

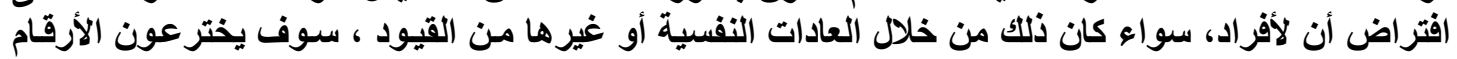

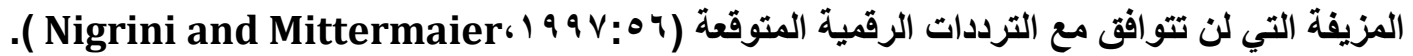

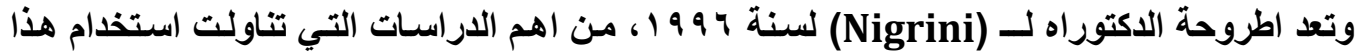

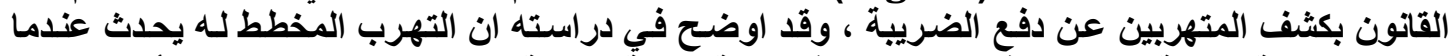

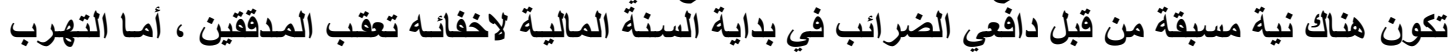




\section{من الثركات المدرجة فيى سوق العراق لالوراق المالية}

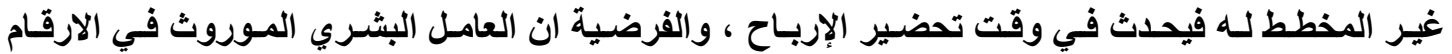

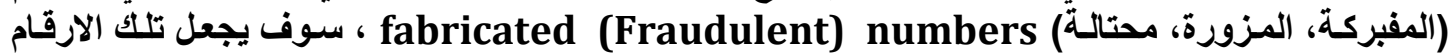

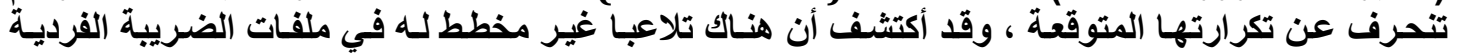

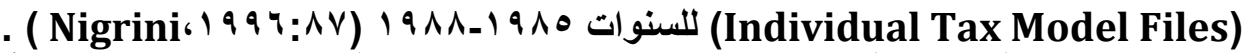

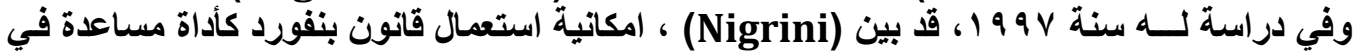

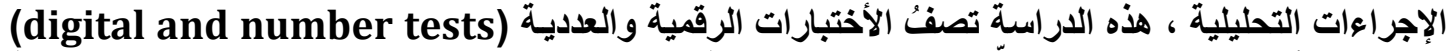

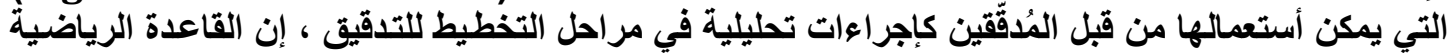

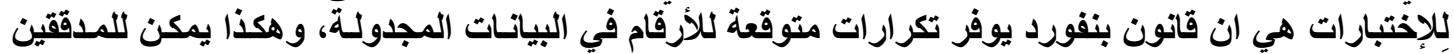

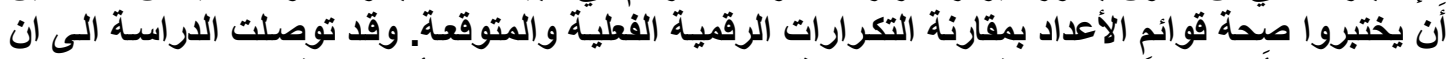

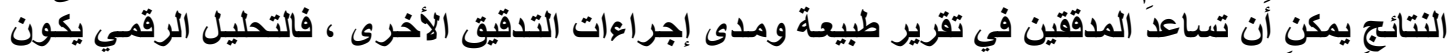

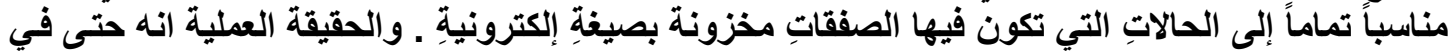

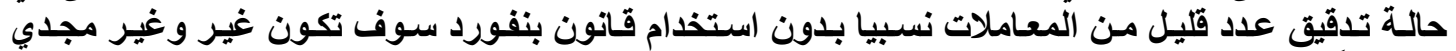

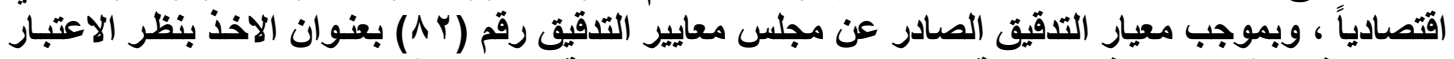

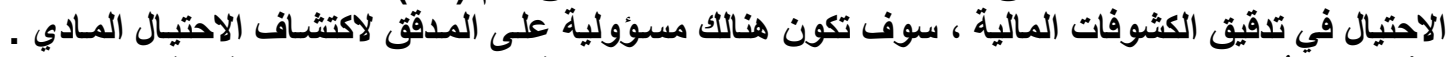

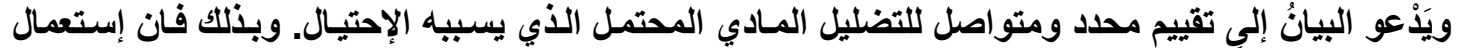

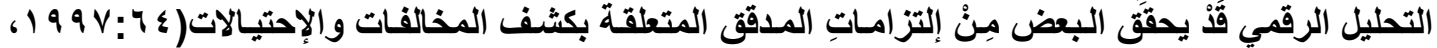

.(Nigrini and Mittermaier

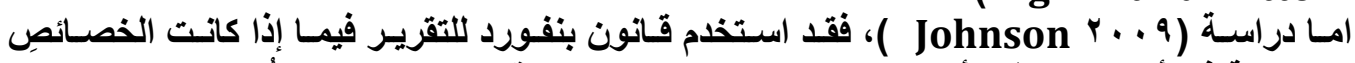

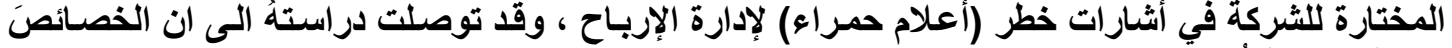

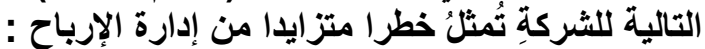

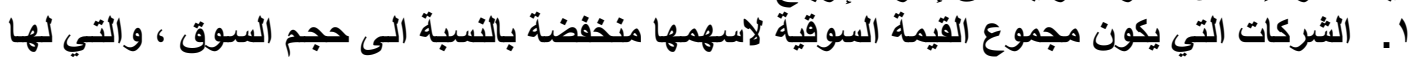

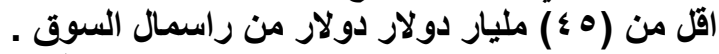

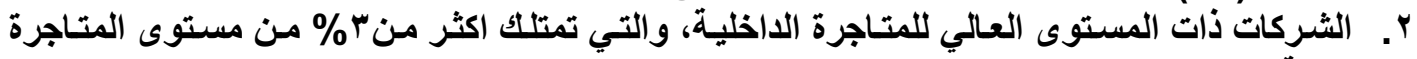
الكلية. r. الثركات المساهمة العامة الجديدة ، وهي الثركات التي يتم تداول اسـهمها من قبل الجمهور ولفترة

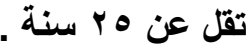

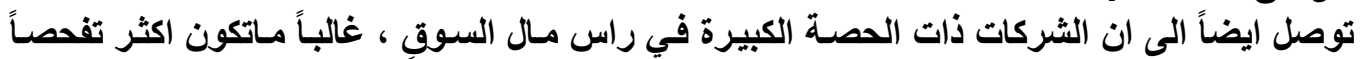

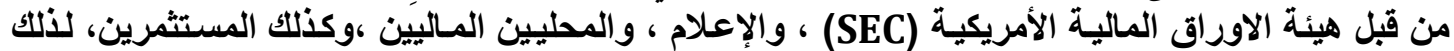

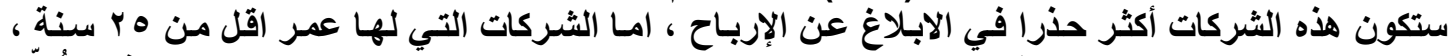

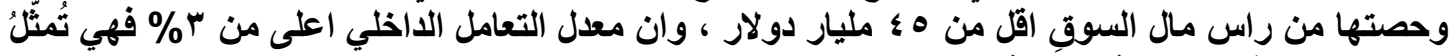

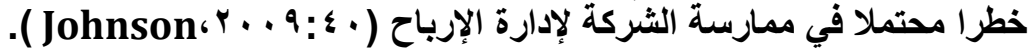


$\operatorname{Prob}(\mathrm{D} 1=\mathrm{d} 1)=\log 10\left(1+\frac{1}{\mathrm{~d} 1}\right) ; \mathrm{d} 1 \in\{1,2, \ldots .9\}$

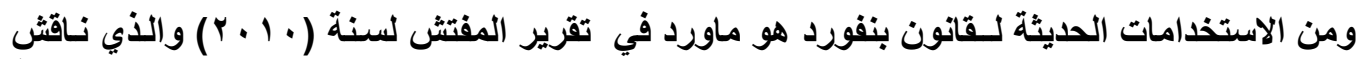

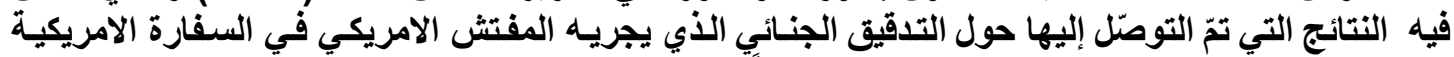

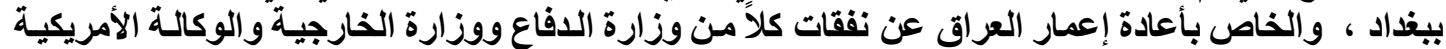

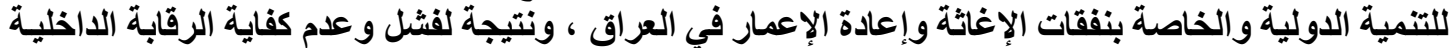

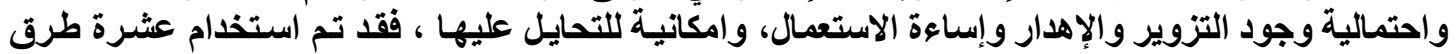

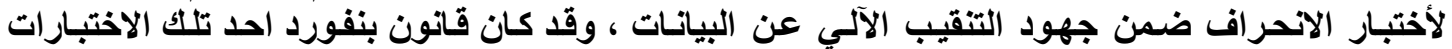

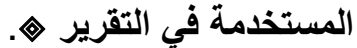

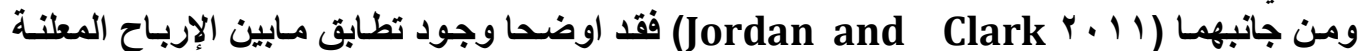

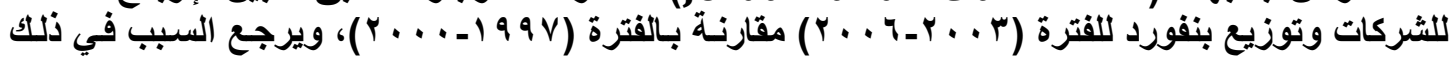

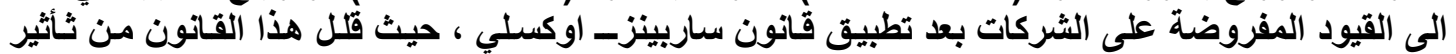

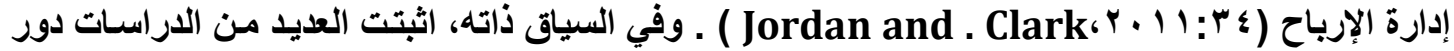

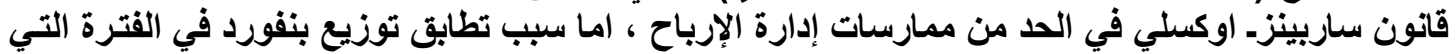

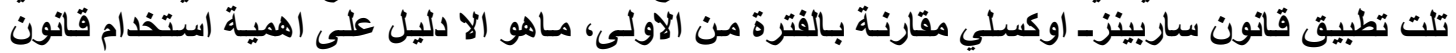

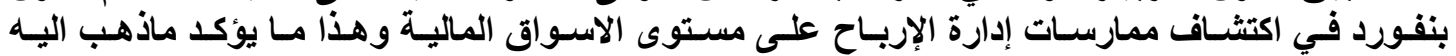

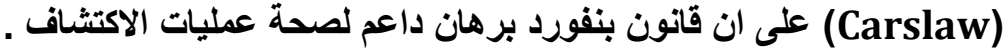

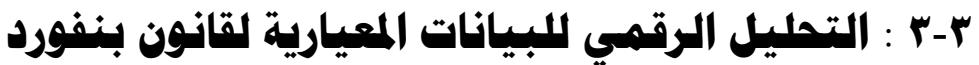

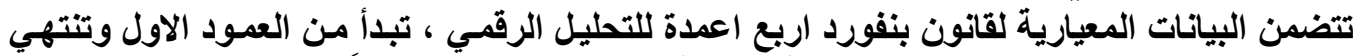

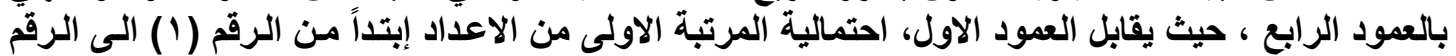

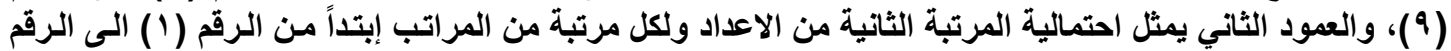

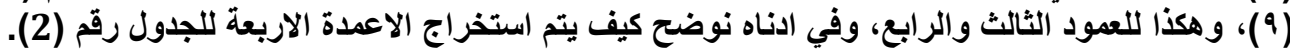

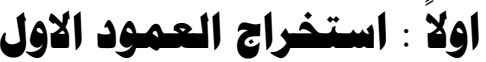

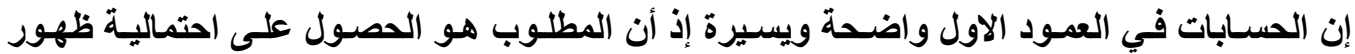

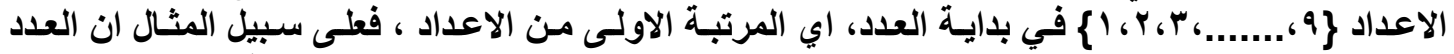

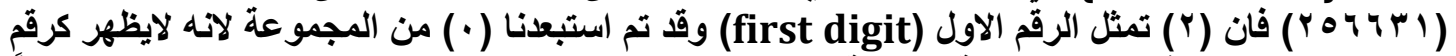

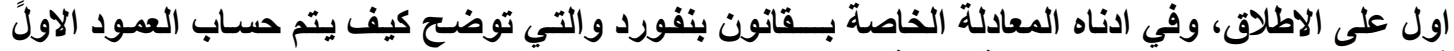

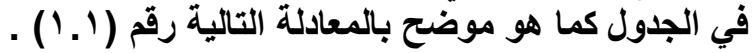

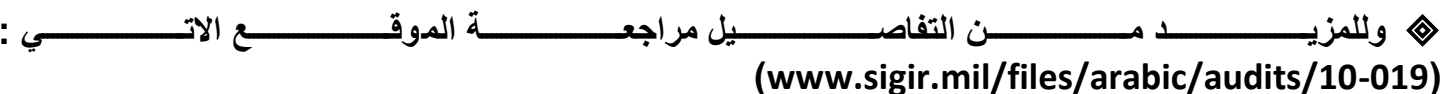

(www.sigir.mil/files/arabic/audits/10-019) 


\section{من الشركات المدرجة في سوق العراق للاوراو المالية}

$=\log 10\left(1+\frac{1}{1}\right)=\log 10(2)=0.30103$

$=\log 10\left(1+\frac{1}{2}\right)=\log 10(3 / 2)=0.17609$

$=\log 10\left(1+\frac{1}{3}\right)=\log 10(4 / 3)=0.12494$

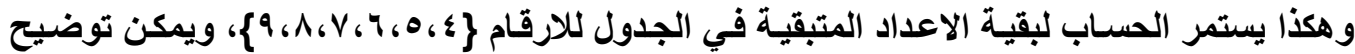

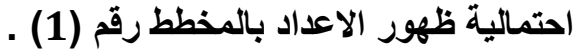

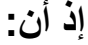

Drob

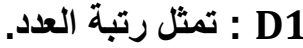

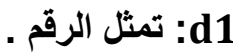

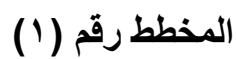

احتمالية ظهور الاعداد في العمود الاول

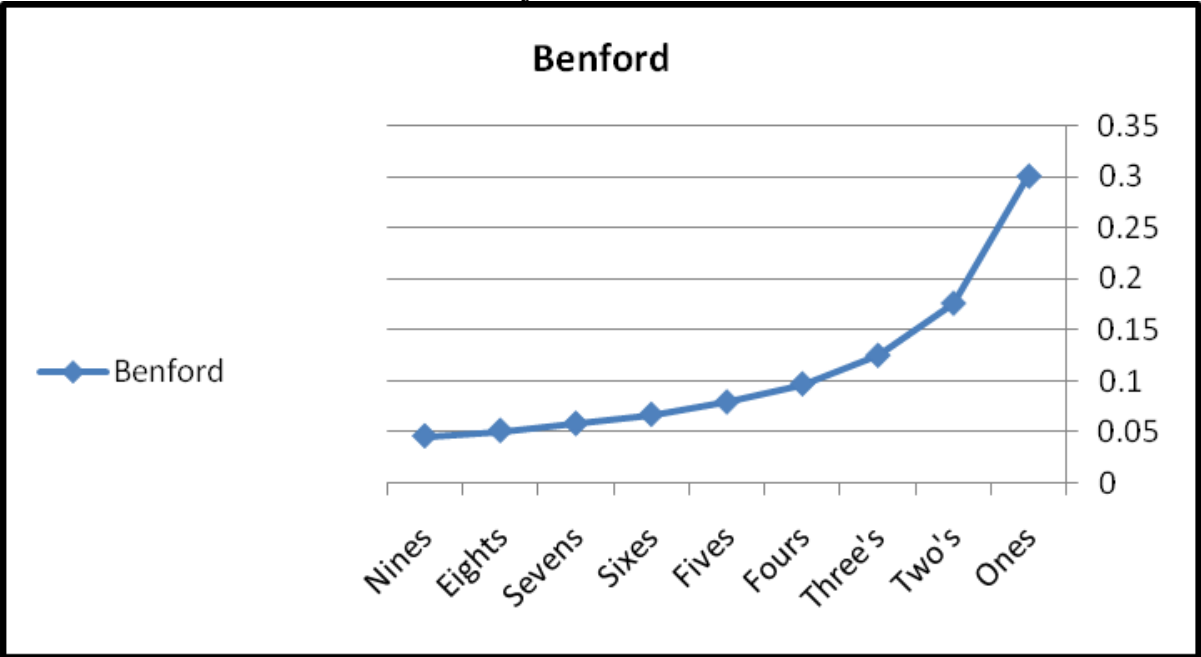

ثانيًاً : استخراج العمهود الثاني

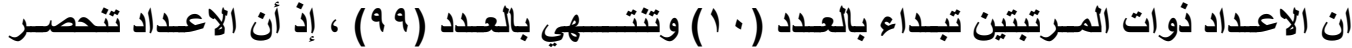

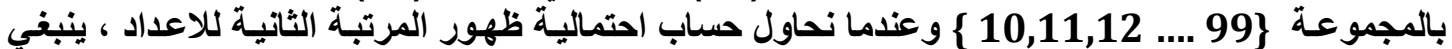
استخدام المعادلة رقم ( أبوع ) وكما هو موضح في ادناه:

Prob $(\mathrm{D} 2=\mathrm{d} 2)=\sum_{\lambda=\mathrm{o}}^{9} \log 10\left(1+\frac{1}{\mathrm{~d} 2}\right) ; \mathrm{d} 2 \in\{0,1, \ldots .9\} \ldots . . .(1.2)$

إذ أن

و2

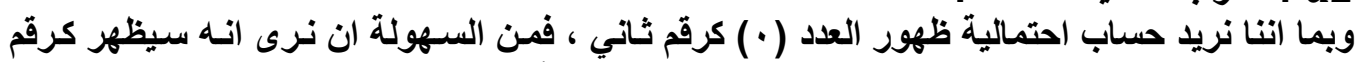

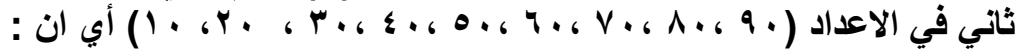


Prob $(\mathrm{D} 2=0)=\sum_{\mathrm{d}=9}^{9} \log 10\left(1+\frac{1}{\mathrm{~d} 2}\right)=$

$\log 10\left(1+\frac{1}{10}\right)+\quad \log 10\left(1+\frac{1}{20}\right)+\log 10\left(1+\frac{1}{30}\right)+$

$\log 10\left(1+\frac{1}{40}\right)+\log 10\left(1+\frac{1}{50}\right)+\log 10\left(1+\frac{1}{60}\right)+$

$\log 10\left(1+\frac{1}{70}\right)+\quad \log 10\left(1+\frac{1}{80}\right)+\quad \log 10\left(1+\frac{1}{90}\right)+\quad=0.11968$

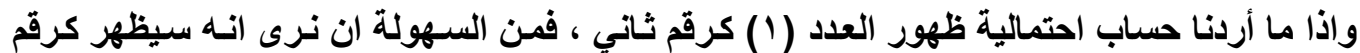

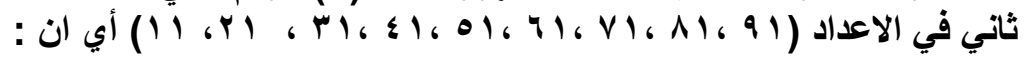

$\operatorname{Prob}(\mathrm{D} 2=1)=\sum_{\mathrm{d}=9}^{9} \log 10\left(1+\frac{1}{\mathrm{~d} 2}\right)=$

$\log 10\left(1+\frac{1}{11}\right)+\quad \log 10\left(1+\frac{1}{21}\right)+\quad \log 10\left(1+\frac{1}{31}\right)+$

$\log 10\left(1+\frac{1}{41}\right)+\quad \log 10\left(1+\frac{1}{51}\right)+\quad \log 10\left(1+\frac{1}{61}\right)+$

$\log 10\left(1+\frac{1}{71}\right)+\quad \log 10\left(1+\frac{1}{81}\right)+\quad \log 10\left(1+\frac{1}{91}\right)+$

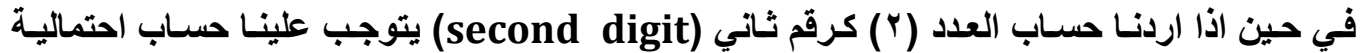

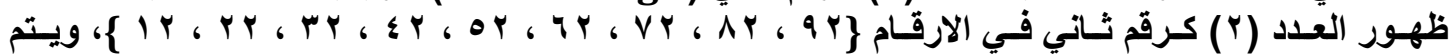

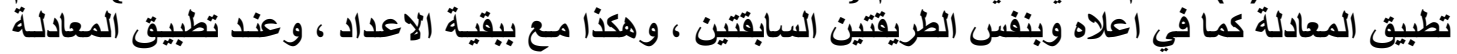

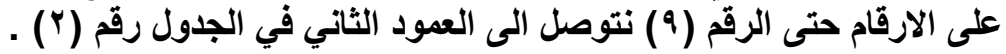

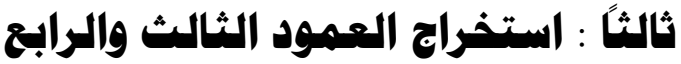

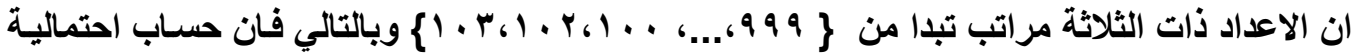

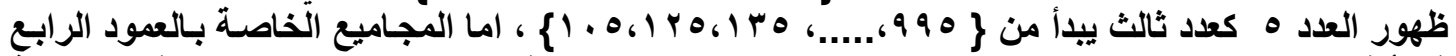

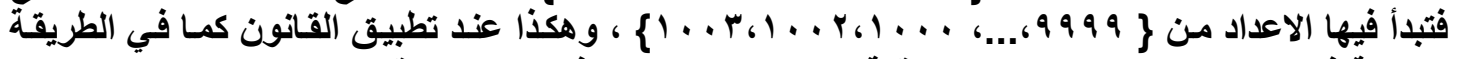

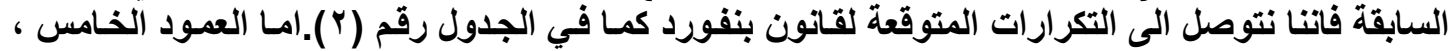

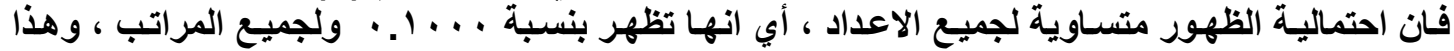

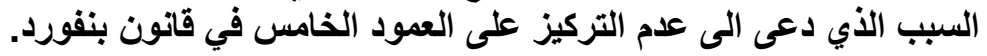

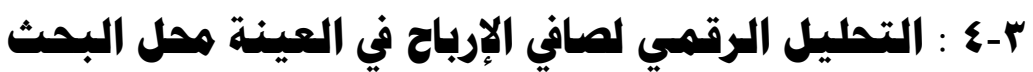

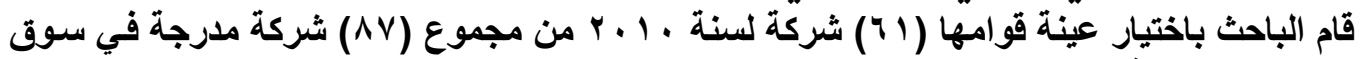

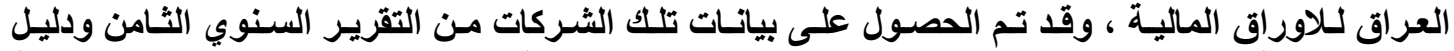

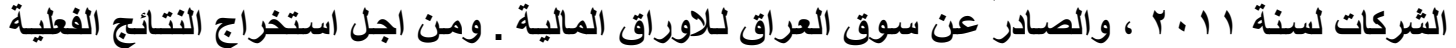

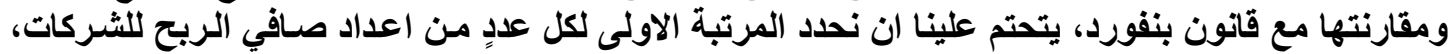

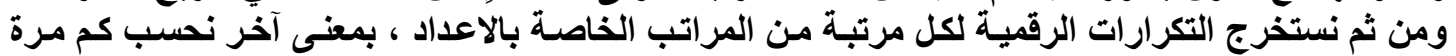

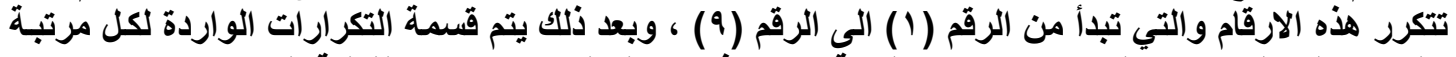

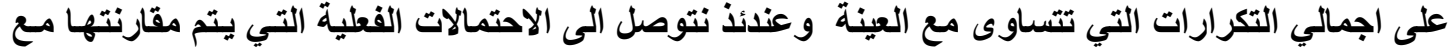




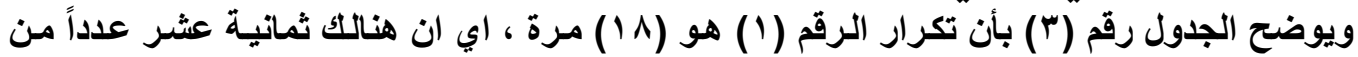

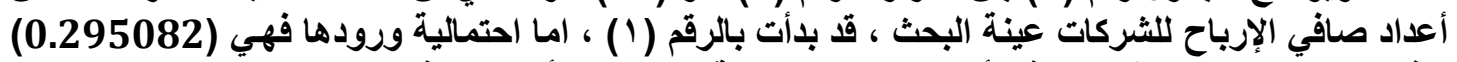

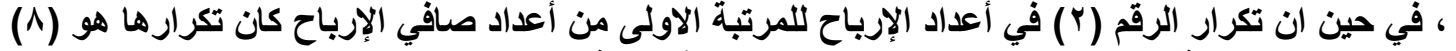

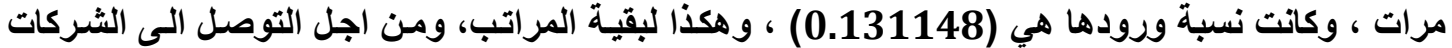

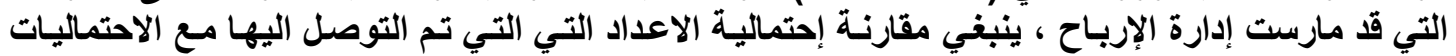

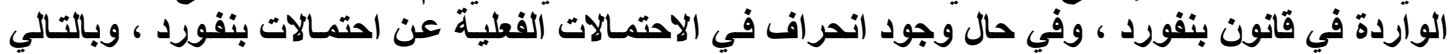

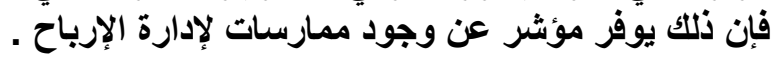

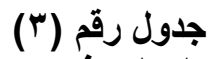

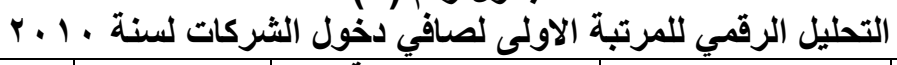

\begin{tabular}{|c|c|c|c|c|}
\hline مراتب الاعداد & التكرارات & للاحتملات الفعلية & Benford's Law & Z-statistics \\
\hline Ones & 18 & 0.295082 & 0.30103 & -0.03829 \\
\hline Two's & 8 & 0.131148 & 0.17609 & 0.753458 \\
\hline Three's & 6 & 0.098361 & 0.12494 & 0.434205 \\
\hline Fours & 5 & 0.081967 & 0.09691 & 0.178106 \\
\hline Fives & 4 & 0.065574 & 0.07918 & 0.156462 \\
\hline Sixes & 4 & 0.065574 & 0.06695 & -0.21314 \\
\hline Sevens & 1 & 0.016393 & 0.05799 & 1.11612 \\
\hline Eights & 13 & 0.213115 & 0.05115 & 5.451425 \\
\hline Nines & 2 & 0.032787 & 0.04576 & 0.178518 \\
\hline
\end{tabular}

يوضح المخطط رقم (r) الاختلاف في الاحتمالات الفعلية والاحتمالات المحدة بموجب قانون بنفورد

و الواردة في الجدول رقم (r) - (r) 
من الشركات المدرجة في سورة العراق للاوراو اللمالية

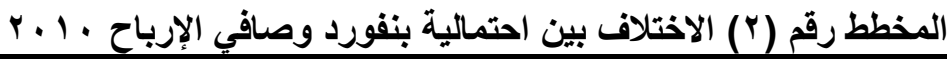

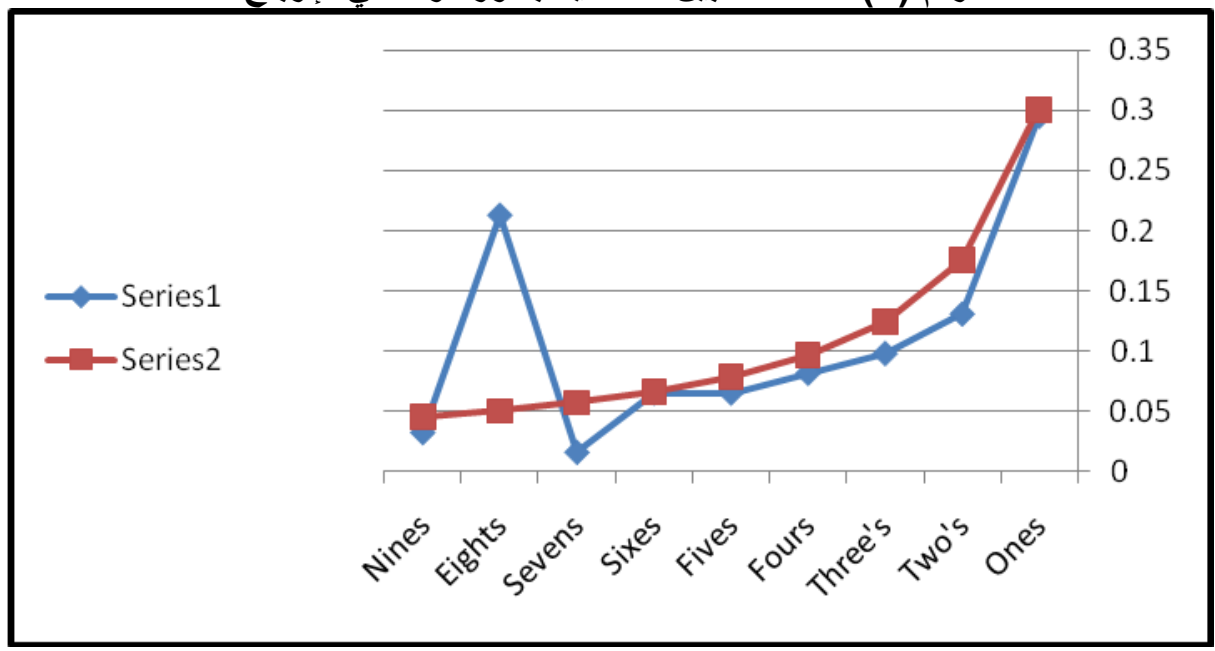

ويمثل المحور السيني المراتب التسعة لكل الاعداد ، امـا المحور الصادي فيمثل الاحتمالية لكل مراتبـة

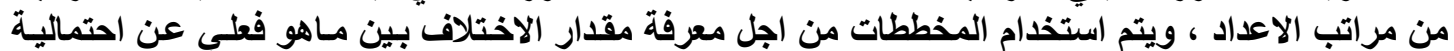

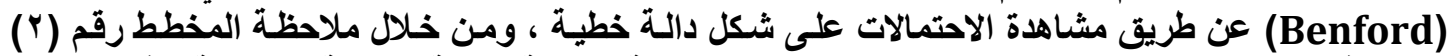

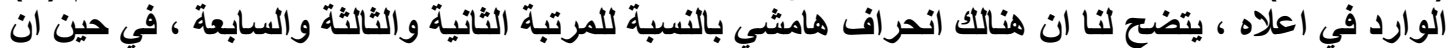

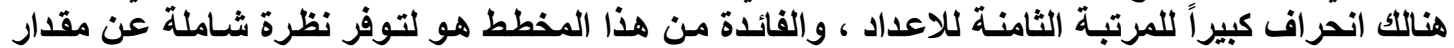

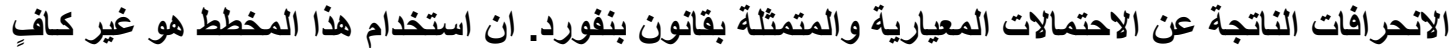

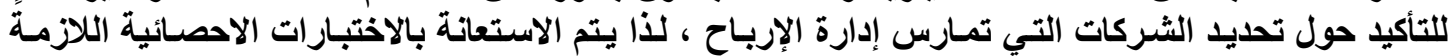

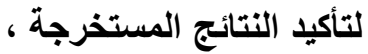

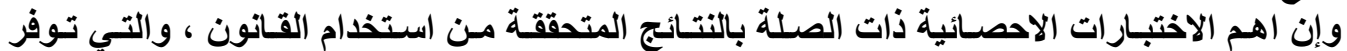

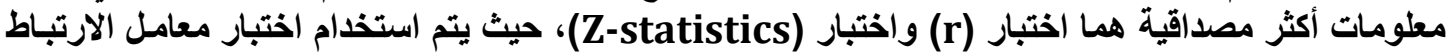

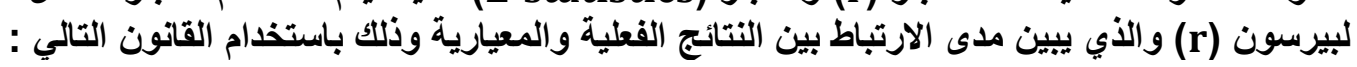

$$
r=\frac{n\left(\sum \text { papd }\right)-\left(\sum p a\right)\left(\sum p d\right)}{\sqrt{n\left(\sum p a^{2}\right)-\left(\sum p a\right)^{2} \sqrt{n}\left(\sum p d^{2}\right)-\left(\sum p d\right)^{2}}}
$$

pa (حتمالية قانون بنفورد.

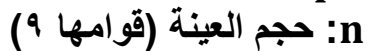

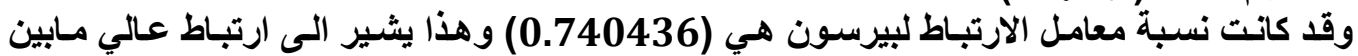

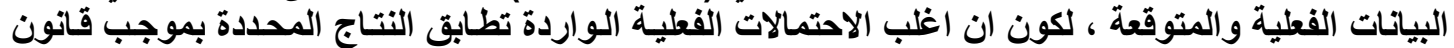
بنفورد ، فالاختلاف بين المراتب الاخرى كان كان بصوره الاحتمالات هامشية . 


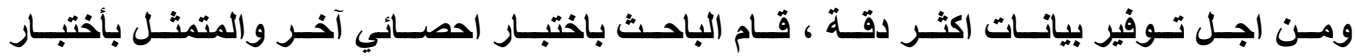

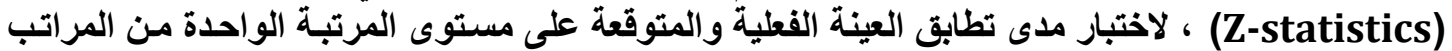

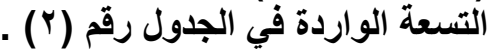

$$
\mathrm{Z}-\text { statistics }=\frac{|p a-p d|-\left(\frac{1}{2 n}\right)}{\sqrt{\left\{\frac{\mathrm{pd} * 1-\mathrm{pd}}{\mathrm{n}}\right\}}}
$$

pa

احتمالية قانون بنفورد.

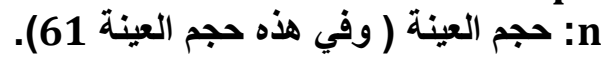
|: القيمة المطلقة.

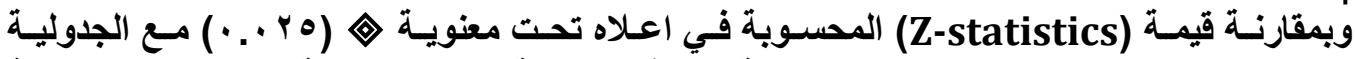

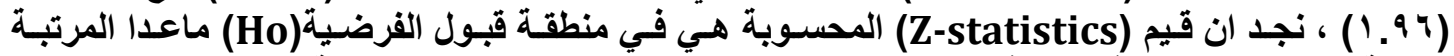

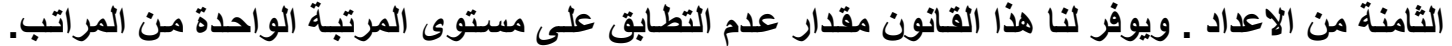

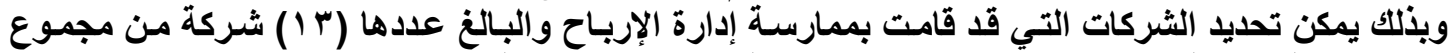

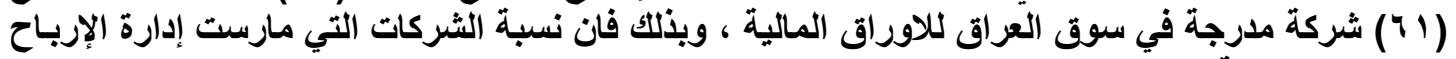

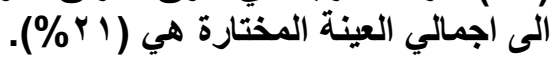
الجدول رقم (ع) (؟) عدد الشركات التي مارست إدارة الإرباح

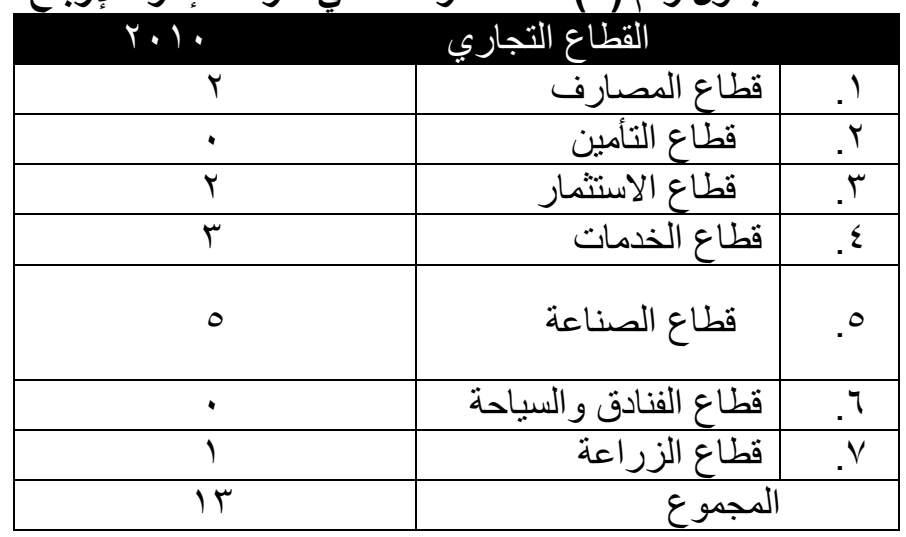

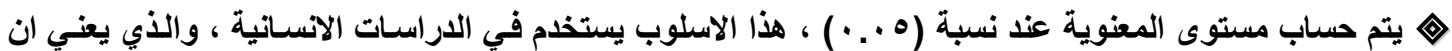

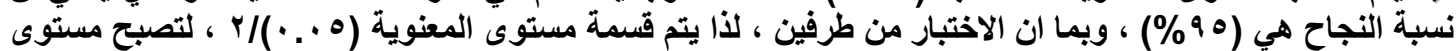

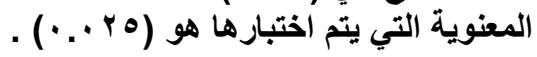




\section{المور الاخير/ الاستنتاجات والتوصيات}

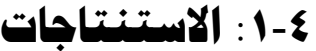

توصل الباحث الى مجموعة من الاستنتاجات في ضوء الإنات الجانب النظري والعملي للبحث وكالاتي:

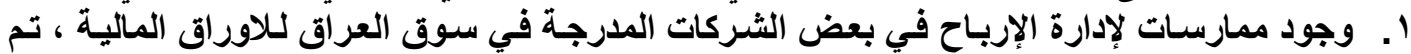

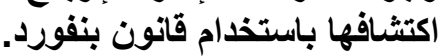

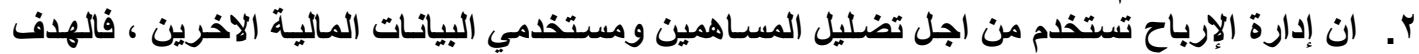

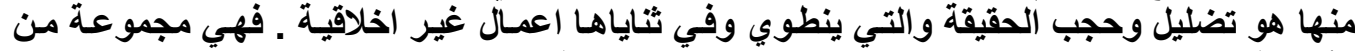

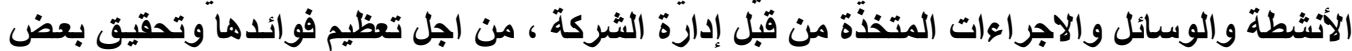

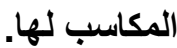

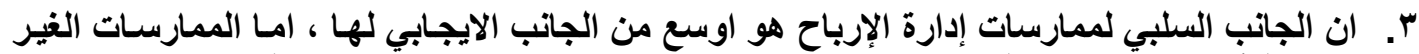

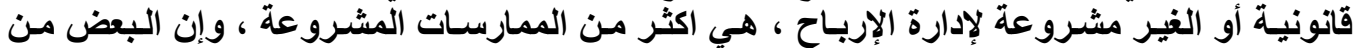

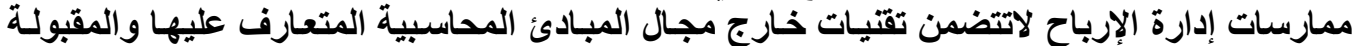

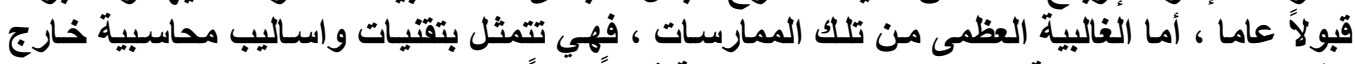

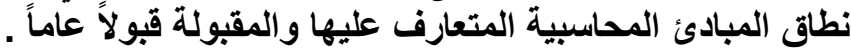

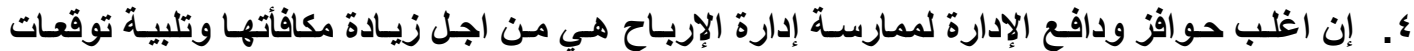

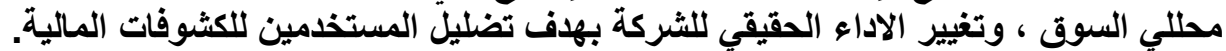

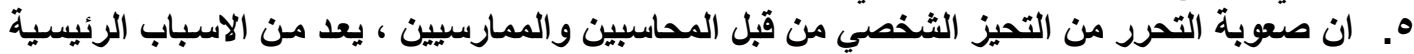

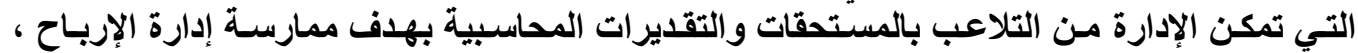

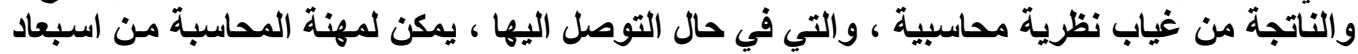

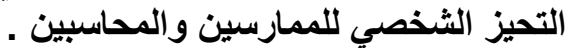

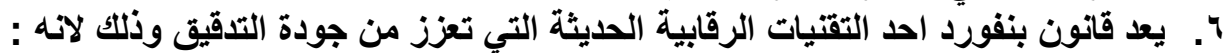

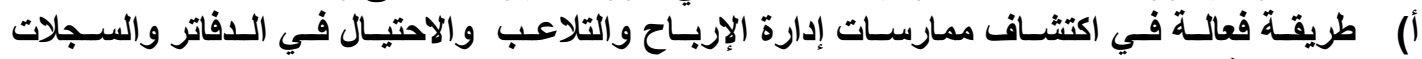
المحاسبية . ب) اكتشاف القيم الغير حقيقية أو أي شي غير طبيعي بالبيانات ، والتي يمكن استخدامها من قبل ممارسي

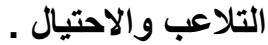

ت) السرعة في تنفيذ عملية التدقيق ، فـان تطبيق قانون بنفورد لايتطلب الكثير من الجهد أو استخدام برامج معقدة. 
يتضمن هذا المبحث مجموعة من التوصيات التي تم يوصي الباحثان بها في ضوء الاستنتاجات التي توصلا إليها الباحثان وكمايأتي :

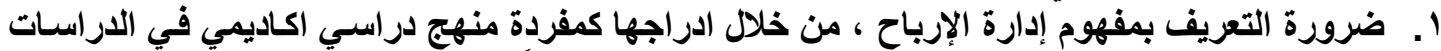

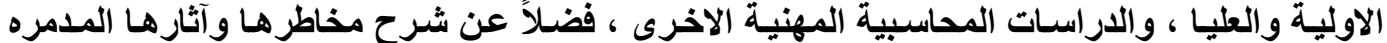

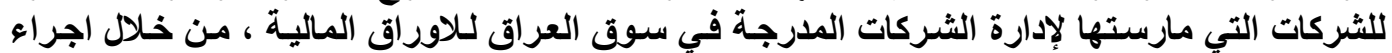

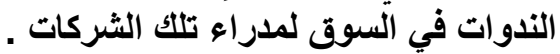

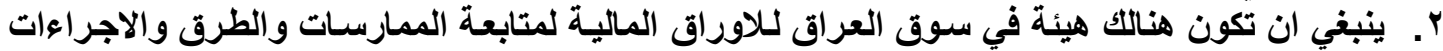

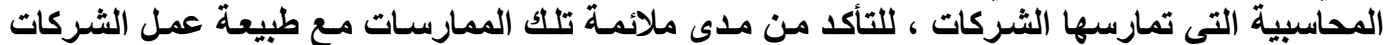

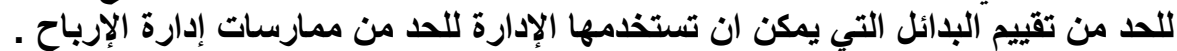

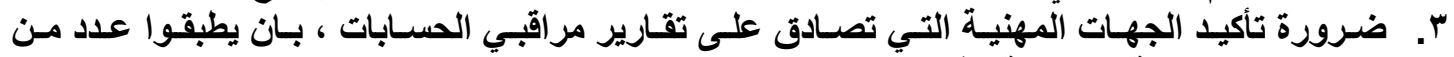

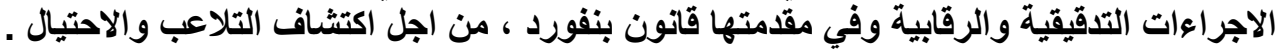

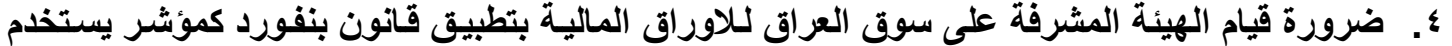

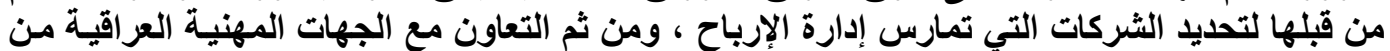

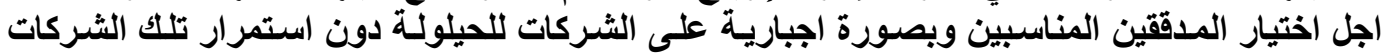

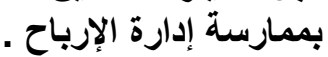

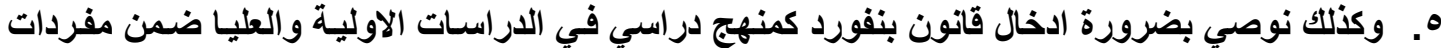

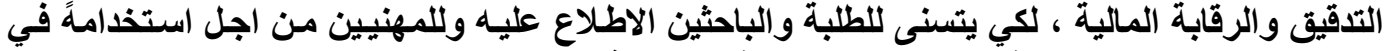

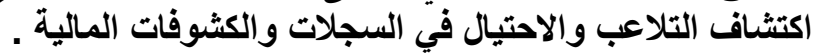

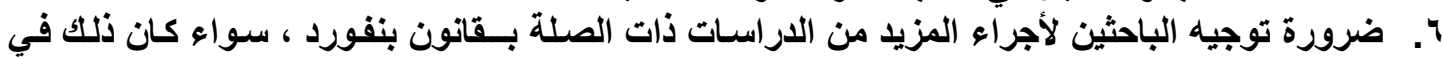

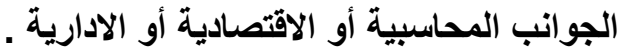

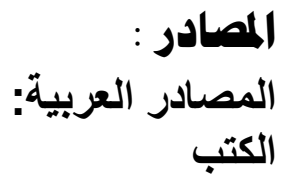

ا ـ . البلقاوي،" نظرية محاسبية"، ترجمة ريـاض العبدالله ، مراجعة طلال الججـاوي ، دار اليازوردي ،

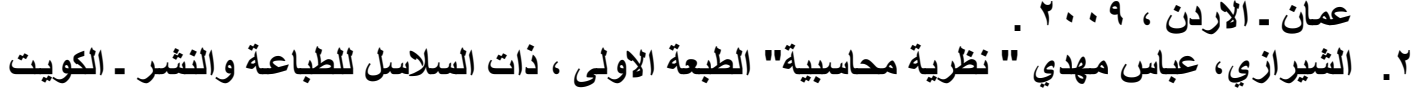
199.6

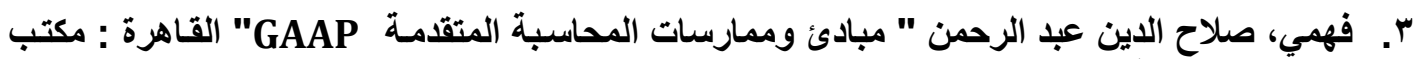

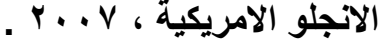

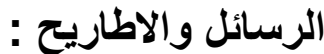

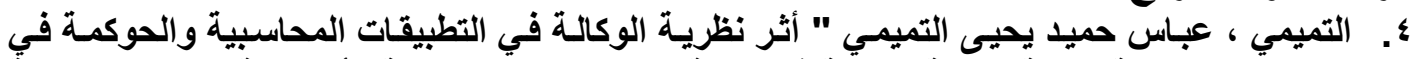

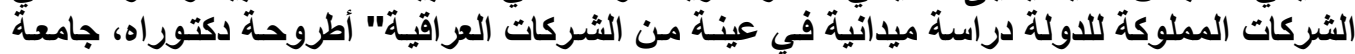

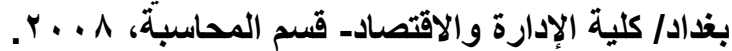

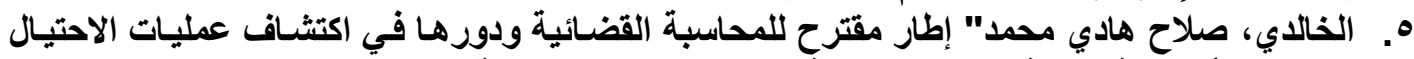

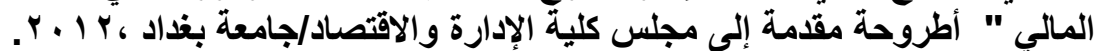

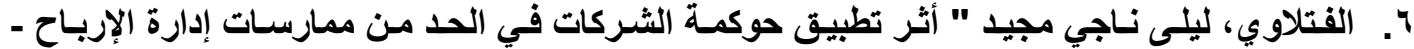

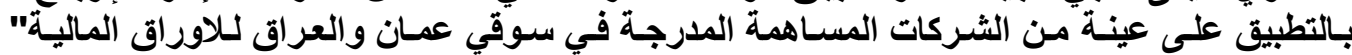

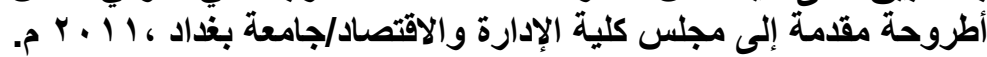


^. نحاس ، محمود نديم ، "التلاعب بالارقام " جريدة عكاظ، العدد ، ج ، r I ، المملكة العربية السعودية

\section{Foreign sources:}

Books:

1. Balkaoui, Ahmed, " Profit measurement, determination, management and the usefulness an Empirical approach ", first published. Quorum Books , London 1999

2. Balkaoui, Ahmed, "Accounting Theory", $4^{\text {th }}$ ed., Business Press-Thomson learning, USA, 200 •

3. Dechow, Patricia M. \& Schrand, Catherine M. Earnings Quality, The Research Foundation of CFA Institute, 2004.

4. Graham, Lynford \& D. R. Carmichhael \& O. RAY Whittington " Financial Accounting and General Topics ", , John Wiley \& Sons, Inc ,2007.

5. Greuning, Hennie van, "International Financial Reporting Standards A Practical Guide", International Bank for Reconstruction and Development / The World Bank, Fourth Edition,2006.

6. Hopwood, William.S, \& Jay J.leiner \& George R,Young "forensic accounting", McGraw-Hill companies,2008.

7. Kieso, Donald E. Jerry J. Weygandt, Terry D. Warfield, "Intermediate Accounting", 13th Edition, , John Wiley \& Sons, Inc, 2010.

8. Mathews, M.R and Perera, M.H.B " accounting theory and development " first published in Australian , 1991.

9. Mulford ,Charles W. and Comiskey ,Eugene E.," The Financial Numbers Game Detecting Creative Accounting Practices", , John Wiley \& Sons, Inc, 2002.

10. Nigrini, Mark J. \& Joseph T. Wells "Benford's Law : Applications for Forensic Accounting, Auditing, and Fraud, John Wiley \& Sons, Inc ,2012,new jersey

11. Schroeder, Richard G \& myrtle W. clark \& jack M.cathey, "financial accounting theory and anylasis : text and cases", , John Wiley \& Sons, Inc, INC, 2009.

12. Scott, William .R. "Financial Accounting Theory" Fifth Edition, Toronto ,Prentice Hall, 2009.

13. Spiceland ,J .David \& James F. Sepe \& Lawrence A. tomassini," intermediate accounting ",McGraw-Hill companies,2007. 


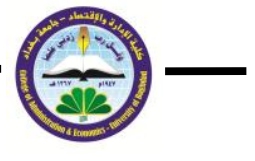

Theses :

14. Babalyan, Levon ," Earnings Management by Firms Applying International Financial Reporting Standards: Implications for Valuation", Presented to the Faculty of Economics and Social Sciences of the University of Fribourg (Switzerland) in fulfillment of the requirements for the degree of Doctor of Economics and Social Sciences, 2004.

\section{Researches :}

15. Badertscher, brad A. \& John D. Phillips \& Sonja Olhoft Rego, "Earnings Management Strategies and the Trade-Off between Tax Benefits and Detection Risk: To Conform or Not to Conform", The Accounting Review; no:1, P63-97،2009.

16. Benford, Frank . 1938. The law of anomalous numbers. Proceedings of the American Philosophical Society. 78(4):551-572

17. Burksaitiene, Daiva ," MEASUREMENT OF VALUE CREATION: ECONOMIC VALUE ADDED AND NET PRESENT VALUE" , ECONOMICS \& MANAGEMENT: 2009. 14, ISSN 1822-6515

18. Carslaw, Charles A. P, N. Anomalies in Income Numbers: Evidence of Goal Oriented Behavior, THE ACCOUNTING REVIEW, Vol. LXm, No. 2, April 1988 .

19. Fazeli, Yasin S. \& Habib A. Rasouli,"Real Earnings Management and the Value Relevance of Earnings "International Research Journal of Finance and Economics ISSN 1450-2887 Issue 62 (2011)

20. Guan, Liming \& Fengyi Lin and Wenchang Fang, Goal-Oriented Earnings Management: Evidence from Taiwanese Firms, Emerging Markets Finance \& Trade / July-August 2008, Vol. 44, No. 4, pp. 19-32.

21. Han, J.y. and S.wong, "political costs and Earnings Management of oil companies during the 1990 persian Gulf crisis", the Accounting review, vol. 73, PP. 103 -117. 1998.

22. Healy,P.M. and J.M. wahlen, "Are view of the earnings Management literature and its implications for standard setting". Accounting Horizon , vol.13, PP. 365-383. 1999.

23. Higgins, Huong N. , "Do stock-for-stock merger acquirers manage earnings? Evidence from Japan" ، Journal of Accounting and Public Policy,2012.

24. Hill, Theodore P., base - invariance implies Benford Law, Proceedings of the American Mathematical Society ,vo 123, No. 3 March 1995

25. Hillison, William \& Cindy Durtschi \& and Carl Pacin ${ }^{n}$, The Effective Use of Benford's Law to Assist in Detecting Fraud in Accounting Data, Journal of Forensic Accounting1524-5586/Vol.V(2004), pp. 17-34, 2004

26. Johnson , Gary C. Using Benford's Law to Determine if Selected Company Characteristics are Red Flags for Earnings Management, Journal of Forensic Studies in Accounting and Business, 2009. 


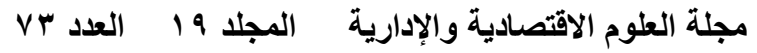

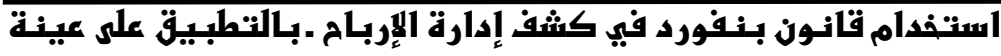

من الشركات المدرجة في سوق العراق للاوراق المالية

27. Johnson, Peter Johnson ,Fraud Detection with Benford's law, Accountancy Ireland، August 2005 Vol.37 No.

28. Jordan, Charles E. and Stanley J. Clark, Detecting Cosmetic Earnings Management Using Benford s Law, the CPA Journal, v o I . L X X X I / n o . 2 February 2011

29. Lin, Feng-Li," Is Earnings Management Opportunistic or Beneficial in Taiwan? Application of Panel Smooth Transition Regression Model" International Journal of Economics and Finance Vol. 3, No. 1; February 2011.

30. Mark G. Simkin," "Using Spreadsheets and Benford's Law to Test Accounting Data “ ISACA Journal, v o 1, 2010 .

31. Newcomb, Note on the frequency of use of different digits in natural numbers, journal American mathematic. 4 (1881) 39-40.

32. Nigrini, M. J. 1996. Taxpayer compliance application of Benford's law. Journal of the American Taxation Association. 18( 1 ):72-92.

33. Nigrini, Mark J. and Steven J. Miller, Data Diagnostics Using Second-Order Tests of Benford's Law , American Accounting Association, auditing: Journal of Practice and Theory, Vol. 28, No. 2, November 2009 ,pp. 305-324 .

34. Nigrini, Mark; "I've Got Your Number - How a mathematical phenomenon can help CPAs uncover fraud and other irregularities", Journal of Accountancy,P:79-83, May 1999.

35. Nigrini،Mark $\mathbf{J}$ and Linda $\mathbf{J}$, Mittermaier, The Use of Benford's Law as an Aid in Analytical Procedures" Auditing,: A Journal of Practice\& Theory Vol. 16, No. 2 Fall 1997.

36. Mark G. Simkin," "Using Spreadsheets and Benford's Law to Test Accounting Data "ISACA Journal, v o 1, 2010 .

37. Thomas, J. K. "Unusual patterns in reported earnings" The Accounting Review, Vol. LXIV, No. 4, 73-787, 1989.

38. Tommie W. Singleton "Understanding and Applying Benford's Law" ISACA Journal Volume3, 2011.

39. Yip, Erica et al "Corporate Social Responsibility Reporting and Earnings Management: The Role of Political Costs" AAFBJ | Volume 5, no. 3, 2011

Publications:

40. ISA 240, INTERNATIONAL STANDARD ON AUDITING 240 THE AUDITOR'S RESPONSIBILITY TO CONSIDER FRAUD IN AN AUDIT OF FINANCIAL STATEMENTS (Effective for audits of financial statements for periods beginning on or after December 15, 2004. 
Using Benford's law to detecting earnings management

Application on a sample of listed companies in the Iraqi market for securities

\begin{abstract}
The net profit reported in the annual financial statements of the companies listed in the financial markets, is considered one of the Sources of information relied upon by users of accounting information in making their investment decisions. At the same time be relied upon in calculating the bonus (Incentives) granted to management, therefore the management of companies to manipulate those numbers in order to increase those bonuses associated to earnings, This practices are called earnings management practices. the manipulation in the figures of earnings by management will mislead the users of financial statements who depend on reported earnings in their decisions. Because it did not honestly reflect the operational results of the companies, therefore are resorting to Benford's Law is use to identify the companies that might be manage their earnings management, Where is this law is conceded one of the monitoring tools that have been used to detect the risk of earnings management, we Use Benford's law to detect the companies that practiced earnings management in a sample of listed companies in the Iraqi stock exchange, The sample consisted of (61) companies from the (87) companies Listed on the market for the year 2010 , We concluded that there are a number of companies that practiced earnings management

key words/ Earnings Management- Benford's Law- Digital analysis.
\end{abstract}

